\title{
Trichome Management to Enhance Camptothecins in Camptotheca Decaisne
}

\author{
Shiyou Li, Zhizhen Zhang, Ping Wang and Wei Yuan
}

National Center for Pharmaceutical Crops, Arthur Temple College of Forestry and Agriculture, Stephen F. Austin State University, Nacogdoches, TX 75962, USA

\begin{abstract}
Inducible chemical defenses of plants have received much attention in the last three decades, and these defenses often involve trichomes. It is known that some plant secondary metabolites may accumulate in trichomes which can protect plants from damage by herbivores. However, studies on plant trichomes are largely limited to some major vegetable or cash crops and model species with large glandular trichomes (e.g., Nictotiana and Arabidopsis). In fact, the existing studies on the effect of damage (pruning or defoliation) on trichome density or chemical production in plants are partial and even contradictory. Management strategies to maximize chemical induction in medicinal plants or pharmaceutical crops have not been developed well. Our experiments showed that camptothecins (CPTs) are primarily accumulated in glandular trichomes in Camptotheca. We found that pruning, particularly decapitation pruning (T-pruning) can effectively induce contents and derivatization of CPTs in Camptotheca, and the leveled CPTs caused induced endogenous autotoxicity (abnormal morphogenesis) in the plants. Auxin reduction is a trigging factor for such induced biosynthesis and endogenous autotoxicity. Because trichomes are visible to the naked eye and can be much more easily targeted and measured than CPTs, the term "Trichome Management" is used for strategy development to induce CPTs in Camptotheca.
\end{abstract}

Keywords: Camptotheca, chemical induction, camptothecins (CPTs), induced endogenous autotoxicity, pharmaceutical crops, T-pruning, trichome management.

\section{INTRODUCTION}

Plant secondary metabolites (SMs) have been proven to be one of the major sources of drugs [1]. Isolation and identification of new bioactive SMs from plants have been one of the major efforts in natural product chemistry. However, SMs may occur only in minute concentrations in plants, so that it is difficult to obtain substantial quantities for drug manufacturing or even for investigational studies [2]. In some cases, SMs may occur in plants at too low concentrations to be isolated and identified with current technology.

To solve these problems, great efforts have been made to develop more sensitive detection and efficient isolation technologies. There is also great interest in developing biotechnological methods to enhance production of specific bioactive SMs in plants for example, election of high yielding cell line, media modification, precursor feeding, elicitation, large scale cultivation in bioreactor system, hairy root culture, plant cell immobilization, and biotransformation. Biotechnological production of desired compounds in plant cell cultures seems the most interesting alternative, but to date there have been very few successful commercial examples due to a lack of understanding of how these metabolites are synthesized and how their synthesis is regulated [1]. Plant metabolic engineering is the redirection of one or more enzymatic reactions in plants with goals to improve the production of existing desired compounds, produce novel

\footnotetext{
*Address correspondence to this author at the National Center for Pharmaceutical Crops, Arthur Temple College of Forestry and Agriculture, Stephen F. Austin State University, Nacogdoches, TX 75962, USA;

Tel: 936-468-2071; Fax: 936-468-7058; E-mail: lis@sfasu.edu
}

compounds that are either new to the species or nature, or mediate the degradation of compounds [3]. Thus, it is possible that transgenic plants have desirable biological and ecological traits. A successful example of metabolic engineering is the induced production of new natural products in $\mathrm{Ca}$ tharanthus roseus cell culture [4]. However, metabolic pathways are controlled at multiple levels and manipulation of single genes is of only limited value in metabolic engineering [3]. The effects of modulating single enzymatic steps are often absorbed by the system in an attempt to restore homeostasis [3]. Thus, recent interests have shifted towards more complex and sophisticated strategies, in which several steps in a given pathway are modified simultaneously to achieve optimal flux [3]. Obviously, metabolic engineering requires thorough knowledge of all the steps in a pathway and the genes encoding these steps. Therefore, the technology may not be widely demonstrated in different plants in the near future.

Existing studies in biotechnological strategies or metabolic engineering focus primarily on plant cell culture with little application in intact plants. In fact, however, plants are more complex factories to produce SMs than either their cells or organs. Some of the most interesting compounds isolated from the host plants occur only in very small amounts or are not all produced in plant cell cultures, despite many attempts to optimize growth and production media and cell line selection [1]. It is well known that plants may have an array of defense reactions including physiological and morphological changes and accumulation of SMs in response to stresses or elicitors. Elicitation, in particular the production of phytoalexins, has been well investigated in some plants [1]. The mechanism of elicitation is poorly un- 
derstood because the experiments with plants are more complicated. To date, no feasible elicitation method has been developed to induce biosynthesis and derivatization of desired compounds in planta. The use of intact plants as a reactor for derivatization of desired compounds has not been addressed.

\section{EXISTING STUDIES ON PLANT TRICHOMES AND DEFENSIVE CHEMICALS}

Trichomes are hair-like appendages extending from the epidermis of aerial tissues of plants. They are among the first anatomical features recognized by the early microscopists of the $17^{\text {th }}$ century [5]. Trichomes may be uni- or multicellular, glandular or non-glandular, and of several morphological types (e.g., straight, hooked, stellate) [6]. Glandular trichomes are common throughout the flowering plants [7]. A variety of natural products, including alkaloids, terpenoids, and phenolics, accumulate in the glandular trichomes of some plants [5], and many of these substances appear to be synthesized within the trichomes themselves [8-10]. It is well-known that trichomes can protect plants from damage by herbivores. However, studies are largely limited to some major vegetable or cash crops and model species with large glandular trichomes (e.g., Nictotiana and Arabidopsis). The common goal of such studies is either to enhance biological control or to improve anti-pest/disease plant breeding [11].

\section{Induction of Trichomes/Chemicals}

Over the past several decades, there have been numerous reports about the induction of SMs by herbivory, and mechanical damage has been extensively investigated in many vegetable or cash crops and model species. Given the large database, it seems reasonable to expect that damage (either herbivory or mechanical damage) to plant tissues can result in an increase of SMs and a decrease in nutritional qualities of plants that subsequently reduce rates of herbivore feeding and growth, at least in the short term $[12,13]$. However, existing studies on the effect of damage on chemical production in plants are contradictory; thus, the hypothesis on induced production of SMs by damage has been challenged by many authors.

Induction by Herbivory: Baldwin et al. (1983-1997) found that tobaccos dramatically increase the synthesis of nicotine in the roots after herbivore attack to the leaves [1419]. Agrawal (1998) found that the concentrations of defensive mustard oil glycosides (glucosinolates) and densities of setose trichomes are increased in wild radish (Rhaphanus sativus) by caging a caterpillar larva [20]. In parsnip (Pastinaca sativa), Ceska et al. (1986) found furocoumarins (angelicin, bergapten, psoralen, and xanthotoxin), collectively, can be 25 times higher in concentration in diseased roots compared to unspoiled roots [21].

Induction by Mechanical Damages: The existing studies on the effect of damage (pruning or defoliation) on trichome density or chemical production in plants are partial and even contradictory.

The alkaloids of tobacco, particularly nicotine, are among the best-studied SMs of plants. Scientists have long known that removal of the flowering top of a tobacco plant increases its total alkaloid content, and such an application is standard practice in the production of cultivated tobacco [18]. Decapitation or topping at the onset of flowering is standard practice in the production of cultivated tobacco; it increases the size, weight, and alkaloid content of leaves [22]. This increase in leaf alkaloid content after removal of the flowering top is largely a result of increased nicotine synthesis in the roots [23]. some authors have observed increases in the alkaloid content of undamaged leaves of tobaccos which have undergone real and stimulated herbivory, not to their flowering tops, or apical or lateral buds, but to their fully expanded leaves $[14,18]$. Further, Baldwin found that tobacco plants respond more to mechanical damage (pseudostimulated and simulated herbivory) than to true herbivory (caterpillar feeding) in terms of total leaf alkaloid contents $[14,18]$. Baldwin believed that the reasons for the difference between mechanical damage and true herbivory are: the larvae could chemically interfere with the ability of the plants to recognize and respond to damage and mechanical simulation may inadequately simulate the physical properties of herbivory, as there are actually temporal and spatial differences between the real and the stimulated herbivory [18]. The author thus concluded that a plant's response to damage is determined by how one removes leaf area, not merely by the amount of leaf area removed. Baldwin found that the alkaloidal response in tobaccos is influenced by the timing and amount of cellular damage, rather than the amount of leaf area lost [17]. His experiment showed that plants subjected to gradual damage had a greater increase in undamaged leaf alkaloid than those subjected to sudden damage. Baldwin also found that damage-induced increases in leaf alkaloids protect induced foliage from caterpillar attack [16]. Several other authors reported that the production of trichomes was induced by leaf clipping in tobaccos [24]. The above tobacco studies showed that mechanical damage might significantly affect the SMs in plant than true herbivory.

By using wild radish as a model, however, Agrawal argued that the induced plant responses by clipping damage are minimized because of the absence of herbivore saliva [20]. The negative results have also been reported in some other plants. For example, furocoumarins are found in many Umbelliferae plants and have been reported to be significantly induced in celery by exposure to cold temperature, UV light, and sodium hypochlorite [25], in diseased roots of parsnip [21]. However, Nitao found that no significant effect of artificial defloration (either partially or completely) on total fluranocoumarin content in wild parsnip as either shortor long-term responses [26]. Vincent et al. reported that CPTs in the leaves of Camptotheca acuminata were not induced by their pruning treatments [27]. These authors did not relate these chemical changes with trichomes. In another study, however, Mutikainen and Walls found that different nettle (Urtica) species (subspecies) have different responses to the stimulated herbivory treatments [28]. In their studies, positive effects of leaf clipping on trichome density in newly emerged leaves were only found in the southern subspecies $U$. dioica spp. dioica, positive effects of apical excision on trichome density were only observed in the northern subspecies $U$. dioica ssp. sondenii, both leaf clipping and apical excision have negative effects on trichome density in $U$. urens. No chemical data were presented in their studies [28]. 
Further, it is not clear whether damage-induced response in SMs is similar in greenhouse-grown (pot-bound) plants and the field-grown plants of the same species. For example, one of the most elegantly documented cases of induced phytochemical response is the dramatic increase in quinolizidine alkaloids of lupine (Lupinus) that occurs with hours of leaf damage on greenhouse-grown plants [29-33]. But an examination of native populations of velvet lupine (Lupinus lecophyllus) found no induced alkaloidal response at all [34]. In contrast, Baldwin (1988b) found that field grown wild tobacco plants (Nicotiana sylvestris) have a fourfold increase in leaf alkaloids to respond to defoliation, but pot-bound plants are not inducible. Several days after transplanting the pot-bound tobacco plants into larger pots with more soil, plants may respond to defoliation with even a fourfold increase in the alkaloid content of the undamaged leaves [15, $16,18]$.

Some studies showed that the induced plant responses by damage are minimized even by using the same plant materials $[34,35]$. Others believed that many studies on phytochemical induction contain large amounts of uncontrolled or unexplained variation within treatments, which has created controversial interpretation of results [36]. Fowler and Lawton argued that many experimental studies were poorly designed, were analyzed with inappropriate statistics, and had excessive amounts of variation within experimental treatments [35].

It is also reported that leaf damage affected primary metabolites, such as proteins and sugars, and thus causes changes in the nutritional quality of leaves $[37,38]$. Owuor and Langat reported that the length of time after pruning affected both chemical composition and quality of black tea (Camellia sinensis) [39]. Theaflavins, caffeine, some volatile flavour compounds, flavour index and tasters' evaluation improved as time increased, while thearubigins and some other volatile flavour compounds decreased with time during the period from 3 months to 39 months after pruning.

Induction by Hormones: There are five main classes of plant hormones. Three (auxins, cytokinins, and gibberellins) promote and regulate growth, and two (abscisic acid and ethylene) inhibit growth or promote maturation. Auxins are produces in shoot apical meristems and developing leaves and diffuse from the site of production downward the roots. It is well-known that auxins have functions of augment growth by cell elongation, inhibit growth of lateral buds (dominance), foster growth of ovary wall, prevent leaf and fruit drop, and orient root and stem growth. Indoleacetic acid (IAA) is the best-known naturally occurring auxin, and both 2, 4-dichlorophenoxy acetic acid (2,4-D) and naphthalene acetic acid (NAA) are synthetic auxins. 2,4-D is widely used as an herbicide, while NAA is commonly employed to induce the formation of adventitious roots in cuttings and to reduce fruit drop in commercial crops. Cytokinins generally stimulate cell division, including cytokinesis. Unlike auxin, cytokinins promote the growth of lateral buds, not stem tips. Cytokinins also have other effects, including the prevention of leaf aging, or senescence. Cytokinins move from root upward to shoot. At present, cytokinins (e.g., kinetin) are commonly used in tissue/cell culture medium. Experiment showed that kinetin alone had little or no effect. IAA plus kinetin resulted in rapid cell division and switched the cells to a meristematic course [40]. Gibberellins are made in a variety of organs, such as young leaves, embryos, and roots, and move passively throughout the plant. Gibberellins are primarily involved in regulating plant height. Too little gibberellin results in dwarf plants, but too much results in long, pale, "foolish" stems. Gibberellins also promote seed germination and involve flowering and fertilization, growth of new leaves, young branches, and fruits. Of the more than 80 different gibberellins known, the most commonly used in experimentation is the fungal product gibberellic acid (GA3). Abscisic acid (ABA) conteracts the growth hormones, apparently by indirectly blocking protein synthesis and new growth. ABA begins forming when the plant senses stress such as drought. ABA moves only short distances from its site of production. The main role of ABA is to induce and maintain metabolic slowdown, or dormancy, especially in buds, and closing of leaf's stomata to prevent excess water loss as well as to accelerate the dropping of leaves and fruits. It appears that ABA and GA can sometimes act antagonistically. For example, ABA inhibits stem growth and GA promotes; ABA promotes dormancy and GA relieves it. Since both ABA and GA are derived from a common chemical precursor, mevalonic acid, the biochemical branch point leading to the synthesis of one hormone or the other determines many aspects of the plant's subsequent behavior. Ethylene is a gas whose molecules contain only two carbon atoms and is dispersed from one plant or plant part to another by air. The hormone is produced by ripening fruits, and it stimulates ripening in nearby fruits. It also stimulates the aging and dropping of leaves and fruits and may have an important role in plant self-protection.

The correlation between hormones and alkaloids has been studied well in cell suspension cultures of Catharanthus roseus and tobaccos in last two decades. It seems clear that at least the alkaloids in cultured cells of these species are determined by auxin. Zenk et al. found that a change in the cytokinin and auxin (for example, the removal of 2,4-D) tends to stimulate production of SMs in cell culture of $C$. roseus [41]. Gantet et al. (1998) found that cells cultured in the presence of auxin did not accumulate alkaloids in the same species. The addition of exogenous methyl jasmonate to the cells restored the ability to produce alkaloids. Studies by Pasaquali and his coworkers showed that genes encoding an enzyme essential for indole alkaloid biosynthesis are rapidly down-regulated by auxin in cell suspension cultures of C. roseus [42]. By using tobacco plants, Tiburcio et al. found that at low levels of IAA (c. $1 \mu \mathrm{M})$ callus grows little but makes lots of pyrrolidine alkaloid, while at higher levels (c. $10 \mu \mathrm{M})$, growth is stimulated and the alkaloid synthesis falls [43]. No studies are available on the correlation of hormones and CPTs in cell suspension culture

As plant growth regulators, hormones are used extensively in agriculture because of their positive influence on quality and quantity of crops (Bosabalidis and Exarchou 1995). It has been also reported that some common hormones, NAA, 2,4-D, and GA3 affect the density of glandular trichomes, with regard to the yield and composition of essential oils in aromatic plants or alkaloidal response in plants $[17,41,44-52]$. However, the conclusions from these authors are contrary. Stahl and Wollensah (1986) reported an increase in the density of the floret glandular trichomes by 
more than 20\%, when Achillea millefolium was treated with 2,4-D. Baldwin observed that exogenous applications of auxins (IAA and NAA) to damaged leaves inhibit the alkaloidal response in wild tobacco plants [17]. However, Baldwin beleived that a change in endogenous auxin concentration is probably not functioning as a negative cue that activates the response to damage in tobacco plants [18]. He stated that blocking the transport of endogenous auxin from leaves to the roots with an auxin transport inhibitor (TIBA), or steam girdling, or ethylene failed to induce alkaloidal response in tobacco leaves. Bhaumik and Datta (1989) found each of GA, NAA, and 2,4-D had an optimum dose for increasing the glandular trichome number in Japanese mint (Mentha arvensis var. piperescens) [49]. Chien and Sussex observed that application of GA to wild-type Arabidopsis thaliana plants growing in short-day conditions accelerates the onset of abaxial trichomes [44]. Conversely, these authors found that application of paclobutrazol, a GA biosynthesis inhibitor, to the plants suppresses abaxial trichome initiation. Perazza et al. further discovered that the GA level response correlates positively with both trichome number and trichome branch number in Arabidopsis thaliana [51]. Recently, in contrast, Bosabalidis and Exarchou observed that GA application resulted in a decrease $(11 \%)$ of trichome density in plants of the hybrid Origanum $\times$ intercedens (Lamiaceae) although NAA increase the trichome density by about $17 \%$ [50]. ABA is a hormone inducible by stress. However, Liu et al. (1999) failed to find strong correlation between ABA and CPT in Camptotheca acuminata [53].

Induction by Environmental Stresses: A number of environmental factors have been found to influence a plant's trichome density or chemical response. Beier and Oertli reported that induction of furocoumarins (psoralen, bergapten, isopimpinellin, and xanthotoxin) in celery by exposure to cold temperature, UV light, and sodium hypochlorite. These authors did not relate these chemical changes with trichomes [25].

By Light: Light duration (photoperiod), light intensity, and day/night temperature regimen may affect trichome density and chemical contents in some plants. In Lycopersicon hirsutum, for example, type VI trichome density and sesquiterpene were greater in long-day photoperiod (LD) than in short-day photoperiod (SD) [54-56]. Chien and Sussex found both long-day photoperiod and gibberellin stimulate trichome formation in Arabidopsis thaliana [44]. With Lycopersicon hirsutum f. hirsutum, however, Gianfagna et al. found that trichome density maybe greater in LD than in SD while sesquiterpene zingiberene content was significantly lower in LD than in SD [57]. They also found that in SD, the optimum conditions for zingiberene production were $25 / 20^{\circ} \mathrm{C}$ (day/night). Roy et al. found that Sinapis arvensis decreases trichome density to increase light reception under low light environment [58]. On the other hand, light stimulates proline synthesis in water stressed barley (Hordeum vulgare) leaves [59], and also enhances the ABA-induced accumulation of proline in barley and wheat [60]. Liu et al. reported that shading had no effect on CPT yield in stem significantly increased stem biomass but in Camptotheca acuminata [61]. However, they believed that heavy shade led to elevated CPT yield in leaves.
By Water Stress: Trichome's contribution to drought avoidance may be critical under some circumstances. For example, Grammatikopoulos and Maneatas found that trichome improve leaf water status by entrapping and retaining surface water, thus assisting in its final absorption into the mesophyll in Phlomis fruticosa [62]. On the other hand, water stress in both soil and air may induce trichome formation in some plants. For example, wheat has significantly denser trichomes under the low soil moisture conditions [63, 64]. Similarly, Hoffman et al. reported that severely waterstressed Taxus $x$ media 'Hicksii' produced significantly more taxanes and ABA than did the less stressed plants [65]. Roy et al. found that Sinapis arvensis might increase trichome density to decrease water loss under drought [58]. In contrast, conditions of low evapotranspiration (high humidity and low temperature) not only could slow but also may even truncate the induced response because low evapotranspiration will greatly slow the water loss from plants and consequently the transport of alkaloids to the leaves from roots [18]. Liu et al. reported that flooding led to significant decreases in leaf biomass but no effect in CPT concentration in leaves or stem in Camptotheca acuminata [61].

By Radiation: Ultraviolet-B (UV-B) light has been observed as a potent inducer of flavonoid production in some herbaceous and woody plants such as Beta vulgaris (Chenopodiaceae) [66], Brassica napus (Crutiferae) [67], Cistus ladanifer and $C$. laurifolius (Cistaceae) [68, 69], Cydonia oblonga and Eriobotrya japonica (Rosaceae) [70], Manihot esculentum (Euphorbiaceae) [71], Olea europaea and $O$. chrysophylla (Oleaceae) [72, 73] and Quercus ilex (Fagaceae) [72, 74]. In many plants, nonglandular trichomes contain ultraviolet (UV) absorbing compounds, primarily phenolics such as flavonoids and therefore can absorb the UV-B (280-320 $\mathrm{nm})$ to protect leaves against radiation damage [70, 72-75]. Nagata et al. also observed induction of additional trichome formation on the adaxial surface of mature leaves of Arabidopsis after massive doses (1-3 kilograys) of $\gamma$-radiation from cobalt-60 [76]. They found that a significant increase in trichome number of the seventh leaf when the full expansion of the fifth leaf was irradiated. The results suggest that $\gamma$-radiation induced trichome formation is mediated by mediated by the normal trichome developmental pathway [76]. Trichome density and relative quantities of UV radiation absorbing phenolic compounds, usually decline considerably with leaf age [70].

By Chemicals: It has been found that plants germinated from wild-type Arabidopsis seeds treated with EMS (ethyl methane sulphonate) have caused trichome mutations [77, 78]. Plants grown in elevated atmospheric ozone may increase activities of enzymes associated with general plant defense mechanism. Ozone exposure often causes a surge in the production of the plant hormone ethylene, as well as changes in polyamine metabolism and increases in the activities of several phenylpropanoid and flavonoid pathway enzymes [79].

\section{Mechanisms of Induced Chemical Defenses}

Current hypotheses to explain how SMs change after damage can be either supply-side or demand-side, but both emphasize "defense" function of SMs, particularly of phy- 
toalexins. The supply-side hypotheses posit that SMs accumulate in response to imbalances between growth-related processes and metabolite production [19]. According to these hypotheses, plants do not regulate the production of SMs to any extent, and defenses are most influenced by the availability or supply of SMs. Growth/differentiation balance hypothesis posits that all SMs have an ontogenetically determined phenology and that their synthesis is emphasized during periods of plant differentiation [80]. The process of plant growth largely occurs during different times than the process of differentiation that produces resin ducts, trichomes, spines and so forth. The "carbon/nutrient" model attempts to explain induced changes in secondary metabolism as a result of imbalances between carbon and nutrient requirement for growth and the availability of these resources from the external environment [81]. According to this hypothesis, only when resources exist in excess of growth requirements are they shunted into secondary metabolism. Plants with an excess of carbon relative to nutrients are predicted to have reduced nitrogen-based SMs such as alkaloids. In contrast, environmental factors such as nitrogen fertilization and shade that leaves plants with shortages of carbon relative to nutrients are predicted to increase nitrogen-based SMs and reduce carbon-based SMs. The "substrate/enzyme imbalance" hypothesis argues that SMs accumulate because of "overflow" metabolism, and emphasizes differential enzyme compartmentalization and regulation [82]. Both carbon/nutrient and substrate/enzyme hypotheses present induced metabolites as being essentially "waste products", neither hypothesis precludes the "defensive" sculpting of the overflow metabolites [19].

The demand-side hypotheses posit that damage results in signals that directly regulate secondary metabolism. These models argue that concentrations of SMs are mostly strongly influenced by the plant's need or demand for defense. The generalized stress-response theory argues that plants have hormonally mediated centralized system of physiological responses for coping with many diverse stresses [83]. Optimal defense theories predict that the most valuable parts of a plant should be most protected against herbivores [17, 8486]. The value of a plant part is defined by its contribution to the plant's fitness. During the reproductive phase, flowers and seeds represent the closest approximation to fitness. Indeed it has been found that these organs often contain the highest levels of defensive SMs within the plant [86]. During the vegetative phase, young, fully expanded leaves have the highest photosynthetic rates and thus contribute most to growth $[17,86]$. It is also found that these young leaves often have more defense chemicals than the old leaves. Baldwin believed that there are two systems for affecting the optimal distribution of defense in tobacco plants: a damageinducible system that triggers an increase in root alkaloid synthesis and a plumbing system that ensures greater transport of alkaloid-containing xylem fluid to younger leaves [17].

The active defense response theory is similar but posits far more specificity in the plant's signaling system [87]. This theory postulates that endogenously produced damage cues or cues specific to the invading organism activate specific defense responses. The rapidly induced increases in SMs result from specific signals that control the metabolic path- ways that produce the chemical defense [19]. It is found that sucrose, the major form of sugar transport in the plant's vascular system (phloem) is a signaler [88]. The plant responds to sucrose's signal by increasing or decreasing nutrient flow from leaves to roots, seeds, and storage organs known as "sink" tissues [88]. RNA molecules may also carry signals long distances via phloem, which is known as "plant information superhighway" [89].

To date, there is no study available on mechanism of induced-CPT response in Camptotheca. Liu et al. found that in C. acuminata CPT concentration in leaves declines at $11 \%$ each month from April to October and CPT concentration in leaves decreased with tree age significantly: 16 times lower in 4-yr-old trees than in 2-yr-old trees $[61,90]$. Therefore, Liu et al. hypothesized that "chemical (CPT) defense mechanisms are programmed for early ontogenic stages in C. acuminata" $[61,90]$.

\section{Problems}

Inducible chemical defenses of plants have received much attention in the last three decades, and these defenses often involve trichomes. Theoretically, trichomes and their defensive chemicals (e.g., alkaloids) in plants should be induced (e.g., by stresses). The existing contrary results may be mainly caused by some problems in experimental materials, sampling (sample size, collection methods, and collection time), and data analysis and interpretation. Mechanisms of herbivore-induced responses are well studied particularly in model plants such as tobaccos, tomatoes, and lupines. However, mechanisms of induced responses are not clear at least in most plants. In last 20 years, correlation of hormones and alkaloids have been well studied in cell suspension culture. In contrast, the effects of hormones on alkaloidal biosynthesis in plant systems have been overlooked and few existing studies are contrary. Further, previous authors never correlate pruning, herbivory, and environmental stresses' induced effect on trichome and defensive chemicals with hormones. In fact, interaction between hormones and alkaloids in plants may be much greater than we knew or expected.

The induced response of trichomes and their chemicals in plants may exist only at the certain stages of plant/organ development (e.g., early stage of leaf or stem development) when plant hormones are abundant and can be affected by stresses. It is best to detect the induced response in right time. The existing studies on response time course of induced-chemicals are limited. Moreover, there are little synchronical analyses of the induced chemicals in both targeted tissues (usually young leaves) and other tissues (mature and old leaves, stems, and roots) of plants although it is critical to understand the mechanism of induced defense and transport of chemicals in plants.

Surprisingly, the economic significance of trichome response and its chemical defenses to stresses have remained unexplored. Management strategies to maximize chemical induction in medicinal plants have not been developed well. Unlike secondary metabolites, trichomes are often visible to the naked eye and can be easily targeted and measured. Thus, the term "Trichome Management" [116] is used to develop strategies to induce preferred chemicals in plant trichomes by stress applications. 


\section{TRICHOME MANAGEMENT}

\section{Glandular Trichomes as Accumulation Sites of CPTs}

The existing studies on CPTs yield in Camptotheca by other authors are contradictory, and all are limited to $C$. acuminata since the plant materials of other species and varieties are not available to them. Most studies showed that almost all parts of C. acuminata could yield CPTs with concentrations ranging from $0.004 \%$ to $0.400 \%$ of dry weight [91]. Hsu and coworkers found that the content of CPTs in different parts of $C$. acuminata are at an average rate of 5:10:5:2:15 for roots:root bark:stem bark:stems:fruits [92, 93]. Fruits have the highest CPTs yield according to these authors. This view has been widely accepted and thus fruits are commonly used for CPTs extraction in China [94].

As early as 1957, leaves were reported to have anti-tumor activity [95]. This indicates that leaves contain anti-tumor CPTs. Later, however, little and even no CPTs were detected in leaves by some researchers [96]. In 1996, Liu and Adams also reported that the difference between young and old tissues was less significant in $C$. acuminata. Some other authors, in contrast, stated that leaves had a higher CPT concentration $(0.040 \%)$ than either roots $(0.036 \%)$ or stems $(0.016 \%)$ (on dry-weight basis) [97], and leaves contained abundant toxic CPTs to kill goats feeding on them [98] although these authors did not describe what kind of leaf materials (e.g., leaf age, or location on the trees, or harvest season) were used in their experiments. In 1994, it is found that Chinese Tung people in Guangdong Province have been using extract of young leaves of Camptotheca with alcohol as the solvent for stubborn skin diseases (e.g., skin cancers) for hundreds of years. Lopez-Meyer and his colleagues found that in C. acuminata, young leaves rather than old ones produced up to $0.40 \%$ of CPT (on dry-weight basis), approximately $50 \%$ higher than in fruits and $250 \%$ higher in the bark [99]. More recently, Liu and his colleagues corrected their previous 1996 results and stated that young leaves had higher CPT production than old ones $[53,90]$. The contradictory results from the authors are probably largely caused by sampling and analysis problems (e.g., experimental materials, sample collection, size, and time, and extraction methods). To date, it is widely accepted that young leaves have higher CPT than old ones in C. acuminata. But other Camptotheca taxa have not examed. Even it is true in all Camptotheca species/varieties, how to explain the phenomenon. The accumulation site and distribution patterns of CPTs in
Camptotheca seem critical to understand the CPT biosynthesis pathway, tree improvement, and CPTs production by the trees.

CPTs are a family of alkaloids, which are SMs restricted to plants. Previously, it was believed that SMs have little explicit function in plants. Recently, however, more and more evidences indicated that numerous secondary products play a physiological and ecological role in plants [100]. Our analysis on glandular trichome and CPT include all three species and varieties of the genus including the previous $C$. acuminata, the recently described $C$. lowreyana $\mathrm{Li}$, cultivars 'Katie' and 'Hicksii', and the newly separated species $C$. yunnanensis Dode [94, 101] (Table 1). The results indicated that young leaves have 3-5 times higher CPT concentrations than old ones regardless of species. The higher CPT concentrations in young leaves are attributable to the glandular trichomes (Fig. 1), which are the CPT accumulation sites in the plants. This finding, along with the previous studies on other plants such as Nicotiana and Solanum [6, 102-104] suggests that glandular trichomes in higher plants may commonly produce SMs (e.g., alkaloids) to defend against insect herbivory and microbe attacks.

Our CPT analyses showed that the young leaves in each species of Camptotheca contained 3 to 5 fold higher CPT concentrations than the old leaves (Table 1). This result supports the previous finding that leaves had anti-tumor activity [95] and is consistent with the results from C. acuminata reported by Lopez-Meyer and his colleagues [99]. It is known that several alkaloid-containing plant species have higher alkaloid levels in young leaves than in old leaves [102]. The youngest leaves of Coffea liberica had 75 times higher caffeine levels than the oldest leaves [86]. The youngest leaves of rosette plants of Cynoglossum officinale contained up to 190 times higher levels of pyrrolizidine alkaloid than the oldest leaves [86]. However, trichomes are not mentioned in these studies.

The fact that young leaves have higher CPTs yield could explain the disparity among different investigators' results of CPT analysis of leaves. Although none of the studies had detail descriptions of leaf materials used, it is likely that some authors obtained positive results on CPT yield in leaves [95, 97-99] because the young leaves were used in the analysis, and other authors' negative results [96, 105] might have been caused by the use of old leaves in the tests. In addition, various authors defined "young leaves" differently.

Table 1. Glandular trichome size and density on lower leaf surfaces and CPT concentrations in leaves of Camptotheca.

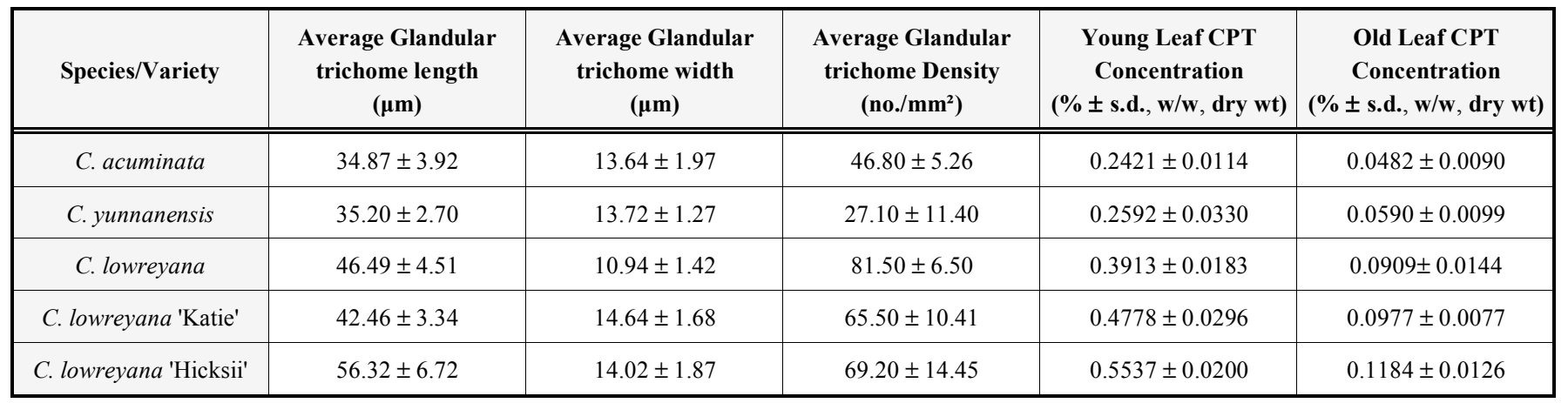




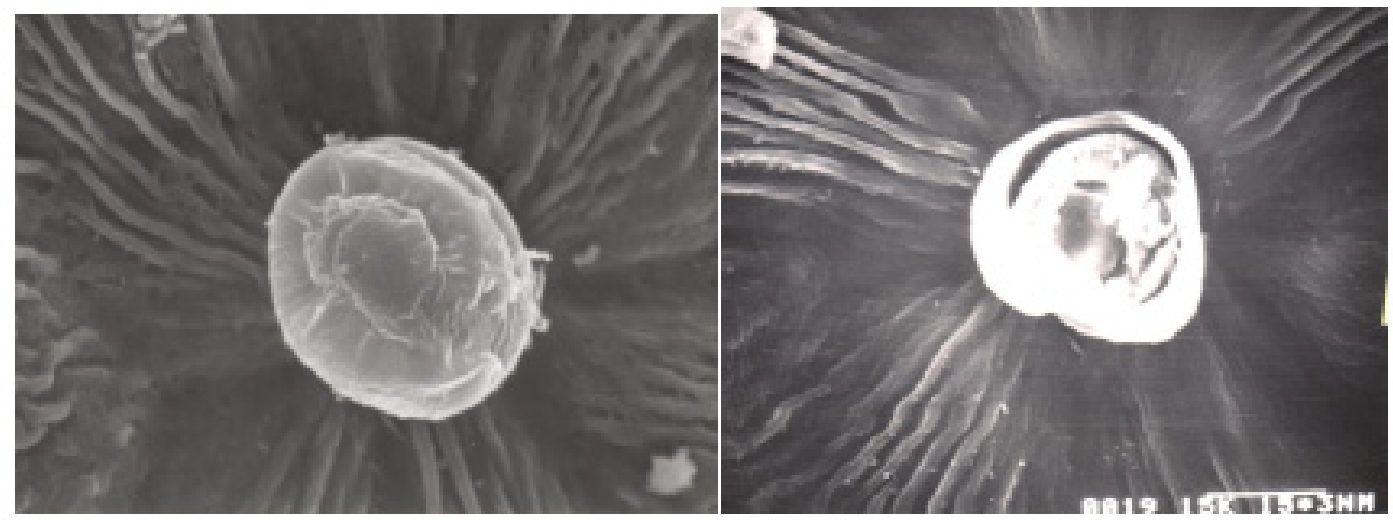

Fig. (1). Intact and broken glandular trichomes of Camptotheca acuminata $(\times 1,000)$.

For example, Liu and Adams defined "young" leaves as that terminal on the branch [105]. However, many terminal leaves are not necessarily young in age, because many branches stop growth in the late stage of the growing season. For this consideration, we define young leaves as those newly spread (mostly less than one week old) [94]. In some cases (e.g., later growing or drought season when plant may cease growing in some tissues), terminal leaves in some branches are not not necessarily young in age. It is also true that branches on upper truck are not necessarily young relative to lower branches. Thus, it is often misleading to determine a young leaf or stem by its location. Liu and Adams did not show a significant difference between new and old leaves since the plant materials used were collected in November when most terminal leaves are not newly spread [105]. The result of young leaves having higher CPT yield also explains that the leaves poisoning goats [98] must be young leaves, which are more susceptible to predation.

Our analysis showed that in Camptotheca young tissues of leaf, stem, and bark produce higher CPT concentrations than old ones (Table 1). The bark of young branches had about 6.3 fold higher CPT concentrations than that of its interior part (wood). In contrast, however, 'sink' tissues (wood, root, and fruit) showed different pattern: CPT concentration in the wood of one year old stem was only about $55 \%$ of the wood of five year old primary trunck; CPT concentration in young roots is only about $15 \%$ of in old roots; while CPT concentration in young fruit (at flower stage) is about $45 \%$ of the mature fruits. These CPT distribution patterns promoted us to investigate where the CPTs accumulation sites are in Camptotheca.

Our recent anatomy of all taxa of Camptotheca under SEM/PEM showed the upper leaf and stem surfaces were covered with wax and only sparsely populated with global glands. Present on the lower surfaces of the leaves of Camptotheca are trichomes, including simple unbranched nonglandular hairs and external unicellular glands [94]. Studies on some other plants such as Nicotiana and Solanum indicated that glandular trichomes accumulate large quantities of metabolic products, which are responsible for plant defense against herbivores [6, 103, 106-108]. Previous studies showed that CPTs were toxic to animals and can be used as insect chemosterilants [98]. Do glandular trichomes in Camptotheca accumulate defensive CPTs?
The following experimental results and facts may provide a positive answer for this question. First, there was a positive correlation between CPT concentration and glandular trichome density and size on leaf surfaces for each of three species and six populations (see Table 1). Secondly, young leaves have the highest photosynthetic rates and thus contribute most to growth. In addition, young leaves contain more nitrogen and water than old leaves and thus provide food of better quality for herbivores. Therefore, young leaves are the most valuable for the plant and at the same time the most vulnerable to herbivory [104].

According to optimal defense theories, the most valuable parts of a plant should be most protected against herbivores [104]. Therefore, we expected that young leaves of Camptotheca should have higher CPTs levels than old leaves. The results of CPT analysis are in accordance with this expectation. In fact, young leaves and branches are not often attacked by herbivores according to our field observations. We also observed that the density of glandular trichomes of young leaves and branches is much higher than on old leaves and stems. Thirdly, glandular trichomes are not found in interior parts of plants (e.g., wood) and there is little or no CPT yield in these parts [91, 94]. Moreover, glandular trichomes experience less damage or loss by freeze-drying than by air- or oven-drying $\left(60^{\circ} \mathrm{C}\right)$ in CPT extraction experiments; as a result, the CPT yield was much higher using freeze-drying than other drying methods [94, 99, 109]. Finally, since it is difficult to have direct CPT analysis on small trichomes $(20-60 \mu \mathrm{m})$, we used an alternative way to detect CPTs in glandular trichomes in Camptotheca. Under $360 \mathrm{~nm}$ UV light (the same wavelength for detection of CPTs in HPLC), we found that on the leaf and branch surfaces, only trichomes, particularly glandular trichomes, showed intense blue fluorescence [94]. This indicated that there were highly concentrated alkaloids including CPTs in the trichomes, particularly in the glandular trichomes. Therefore, we conclude that CPTs are mainly accumulated in glandular trichomes on the leaf and branch surface, especially of young leaves and branches (1-4 weeks old).

McKnight and colleagues believed that CPT, or more likely a water-soluble precursor, is produced elsewhere in the trees and transported to the leaves [110]. Such a transport against a great concentration gradient would be energetically costly for the plant. It is unlikely that the high concentrations 
of CPTs in glandular trichomes are the result of transport from other parts of the plant. Trichomes develop very early in the life of the leaf and atem. CPTs are highly accumulated in the large vacuole of the glandular trichome at the early stage of leaf or stem development (Fig. 3), and then gradually diffuse into parenchymas of leaf and sink tissues (stem wood, roots, and fruits) via phloem. Chloroplasts maybe involve in the biogenesis of CPTs in trichomes. As SMs in vacuole, CPTs are influenced by hormones and thus respond to damage or environmental stresses those influence hormone level and transport. This explains distribution pattern of CPTs in plants.

We found that CPT concentration and CPT yield showed different distribution patterns as leaf develops. CPT concentration decreases as leaf grows: $1.0: 0.5: 0.2$ (young leaf : intermediate leaves: old leaves), while CPT yield per leaf experiences increase and decrease as leaf grows: 1.0 : 3.5 : 2.0 (young leaf : intermediate leaves : old leaves). The reasons can be explain as follows. In young leaves ( $<1$ weeks), trichomes are not fully developed although the trichome number per area (density) is high. From young leaf $(<1$ week old) to intermediate leaf (reaching mature size, 1-4 weeks old), CPT concentration (based on biomass weight) decreases because trichome density decreases caused by increasing surface area and biomass growth. However, CPT content per trichome may increase during this stage, as a result, CPT yield of whole leaf increases relative to in young age. After leaf gets mature, trichome may experience damage or loss and CPT may diffuse and tranport to other tissues although biomass is relatively stable as compared with intermediate leaf. These factors result in decrease of both CPT concentration and yield of whole leaf. Practically, thus, intermediate leaves should be the harvest target for CPT production.

In a conclusion, the major findings of this study included: (1) Different varieties of Camptotheca had significant variations in CPTs concentration, but all can be used as CPTs sources; (2) Young leaves contained significantly higher (3-5 times) CPT concentrations than that in old ones, and thus management of young leaves will be a new approach for CPT production [27]; and (3) Epidermal trichomes, particularly glandular trichomes on the leaves and branches are the accumulation sites of CPTs having the highest CPTs concentration. Therefore, glandular trichomes can be a target in management of Camptotheca for CPTs production by both traditional silvicultural practices (e.g., pruning and other stress management) and modern biotechnology including cell culture and gene technology.

\section{IMPACTS OF PRUNING ON GLANDULAR TRICHOMES AND CPTS}

\section{Pruning Has not been Used in Induced Production of Target Compounds in Plants}

Pruning is the process of removing of a part or parts, living or dead, of a living plant [111]. The main purposes of pruning are to (1) keep plants healthy and attractive, (2) control plant size, (3) improve the quality of flowers, fruits, foliage or stems, (4) reduce hazards, and (5) create unusual plant forms [112].
Apical dominance is a basic principle of pruning. The terminal bud produces a hormone called auxin that inhibits the growth and development of lateral buds. When the terminal bud is removed by pruning, lateral buds and stems below the pruning cut grow vigorously. Because auxin moves downward in the shoot toward the Earth's center, apical dominance is strongest in vertical or upright shoots or limbs. For vertical shoots or limbs, the most vigorous new growth always occurs within 6 to 8 inches of the pruning cut. However, regrowth on limbs having a $45^{\circ}$ to $60^{\circ}$ angle from the vertical will develop farther away from the cut [113].

There are several basic types of pruning techniques commonly used in landscape plants.

Thinning is removal of connecting branches to point of origin or shortening the length of a branch by cutting to a lateral. Thinning will make a plant grow taller and more open. Heading (also known as topping, rounding-over, dehorning, capping and hat-racking) is the pruning of large upright branches between nodes to reduce the height and increase the density of the plant. A selective heading cut removes a branch back to a sidebud or stem, while a nonselective heading cut (also known shearing) removes all the branch tips that are level with the plane where the shears make the cut [112]. Tipping is a practice of cutting lateral branches between nodes to reduce crown width. Both heading-back and tipping are recognized as a poor maintenance practice that harms trees and should not be used in regular tree pruning [114]. Pinching is a common technique for training perennials herbaceous plants. Using the thumb and forefinger frequently pinch back very soft growth (usually whole buds, leaves or stems) throughout the growing season to avoid future pruning, to redirect growth, to increase the density of the plant, or to disbud flowers and thin fruits. Rubbing refers to rubbing off undesirable buds, such as sprouts on the trunk or scaffold branches of a fruit tree, or any young growth that seems to be heading in the wrong direction [112]. There are many kinds of pruning tools, e.g., pruning shears, lopping shears, pruning saws, chain saws, pole pruners and saws.

Pruning has been long used in horticulture and forestry, e.g., landscape plants, fruit plants, and timber trees worldwide. It is a well-known fact that pruning greatly increases healthy biomass growth of plant. Recently, for instance, Ouellette and Young reported that removal of five uppermost immature leaves or short tipping after 20 to $25 \mathrm{~cm}$ of terminal growth produced more lateral budbreak than occurred on nontreated shoots in apple (Malus domestica) [115]. Also, they found that shoot tipping resulted in the highest number of branches and greatest total branch length. Pruning is an essential agronomic practice in tea (Camellia sinensis) production to maintain the tea bushes in a manageable condition for plucking [39]. But it is not clear if pruning induces chemical production in medicinal plants. In fact, the existing data on the effect of pruning on chemical production in plants are partial and even contradictory. Some authors reported that the production of trichomes was induced by leaf clipping in tobaccos and Urtica [24, 28]. In contrast, others argued that the induced plant responses by clipping damage are minimized because of the absence of herbivore saliva [20]. 
Vincent et al. suggested harvesting young leaves of $C$. acuminata for CPT production. In their experiment of greenhouse plants, however, no induced CPTs in the leaves were produced by their treatments [27]. The average CPT yield is only $14.58 \mathrm{mg}$ per plant in 6 weeks which they believed the best harvest interval. In addition, the CPT yield is not constant from plant to plant (CPT concentration range from 0.045 to $0.349 \%$ on the dry weight basis) because actually no standard pruning techniques were developed and applied by these authors in their experimental plants. Their experiment lasted only 12 weeks and no long-term data (e.g., seasonal variation, age variation) were collected.

\section{Effective Pruning: Decapitation (T-Pruning)}

Decapitation (pruning of apical shoots) also known as "T-pruning" method refers to our newly invented pruning techniques for trichome management: to maintain Camptotheca trees in lowering and compact form by special pruning and pinching to increase both biomass yield of young vegetative tissues and trichome density and thus enhance the yield and derivatization of CPTs in these tissues [116]. Lowering compact form of Camptotheca trees is suitable for both manual and mechanical harvests of young vegetative tissues (stem and leaf clipping). The T-pruning techniques can be applied to any age seedlings with either sexual or asexual origin. This invention relates to a method of treating plant matter in manner, which breaks walls of glandular trichomes in young leaves and stems in order to have efficient extraction of CPTs. The walls of the glandular trichomes are thicker than those of the surrounding epidermis. By grinding procedure (e.g., using mortar or grinder), the trichome walls are not broken down well. Ultrasonic or homogenizer treatment can broke the trichome wells and enhance effective extraction of CPTs [116].

Induced Biosynthesis of Target Compounds by Pruning: The CPT content of intact young tissue of Camptotheca was significantly induced by T-pruning treatments. The Tpruning treatment significantly increases CPT content as compared to the control [116]. Annual biomass yield of intact young tissue is also significantly increased by T-pruning treatment [116]. As the result, the total CPT yield of Camptotheca will be expected enhanced by several times by using T-pruning techniques.

We found that decapitation of six month-old C. acuminata seedlings increased CPT contents in intact young tissues ( $\leq 2$ week old leaves and stems) by about $100 \%$ and in whole plants by about $60 \%$, respectively [116] (Fig. 2). It has been found that both CPT content and yield of whole plant or intact young tissues are significantly induced in several days after pinching. However, there are two inducing peaks of the CPT contents by damages (pinching) over a certain time of period for any part of young tissues (leaves, stems, and roots), which, in turn, suggests that there are two steps of defensive response in Camptotheca to damages: first emergence defense and then long-term defense. The emergence response occurs on 2 or 3 days after the pinching according to the present invention. As result of emergency defense against damages, plant increases its contents of CPTs in young tissues (particularly young leaves) largely at the cost of CPTs decrease in old tissues. Thus, the total CPTs contents in a whole plant do not change significantly during the emergence defense. In other words, emergence response may produce a false increase of CPT yield in whole plants. After the emergence response wanes, long-term response occurs during 6-8 days after the pinching according to the present invention. Long-term defense produces greater increase in the contents of CPTs in both young and old tissues than emergence response. Thus, CPTs contents increase significantly in whole plants. To reach the maximum and stable CPT yield, it is more preferred to harvest plant materials after the long-term response starts. The start time of these responses may increase with plant age and size (e.g., height).

In six-year-old mature trees, T-pruning significantly induced changes in both leaf pattern and CPT contents (Fig. 3). The intact young vegetative tissues with enhanced CPT contents (higher than those in fruits) can be a idea sustainable resource for production of CPTs [116].

Without disturbance, almost all leaves in mature trees of C. acuminata have entire margin while leaves during juvenile stage (two year old or younger) are almost exclusively serrated. Surprisingly, however, we found that decapitation in mature Camptotheca induced abnormal morphogenesis in planta: dramatic morphological deviations from normal development [117]. After decapitation in March, almost all newly spread leaves in the mature trees are non-entire (serrate and lobed). The pruning can induce bidentate, bifid, tridentate, and trifid leaves that were never observed in wild Camptotheca. Interestingly, the induced leaf margin pattern simultaneously changed as CPT content over time after treatment. However, pruning without removal of apical buds did not induce either abnormal morphogenesis or CPT content in Camptotheca although all lateral stems or leaves were removed (unpublished data). This suggests that apical pruning (i.e., auxin reduction) induced such abnormal morphogenesis.

Our previous experiment showed that decapitation pruning can enhance shikimic acid accumulation in Pinus taeda seedlings growing in either the greenhouse or fields by about $95 \%$ and $55 \%$, respectively (unpublished data).

Induced Derivatization of Target Compounds: Decapitation pruning can also significantly induce biosynthesis of some alkaloids and triterpenoid glycosides that are not detected or occur at too low a level to be isolated in untreated plants [118-121]. Camptotheca acuminata is one of the most extensively studied species. Its chemical constituents of all tissues have been investigated since the anti-tumor activity of CPT was discovered in 1958 [121]. As a result, 12 natural CPT derivatives were identified until our investigation. Both contents and diversity of the alkaloids were significantly increased by the decapitation pruning technique (the patented "Trichome Management" method) [116]. HPLC chromatograms of CPT and related alkaloids in C. acuminata before and after induction by decapitation are presented in the Fig. (4). The induced production of these minor or new compounds allowed us to isolate more new derivatives of the target compounds. As a result, the PI and his associates have identified two new CPT analogs and two other new compounds from C. acuminata (Fig. 5) [121]. From the root and stem bark of buttonbush (Cephalanthus occidentalis), one of the most common American woody 

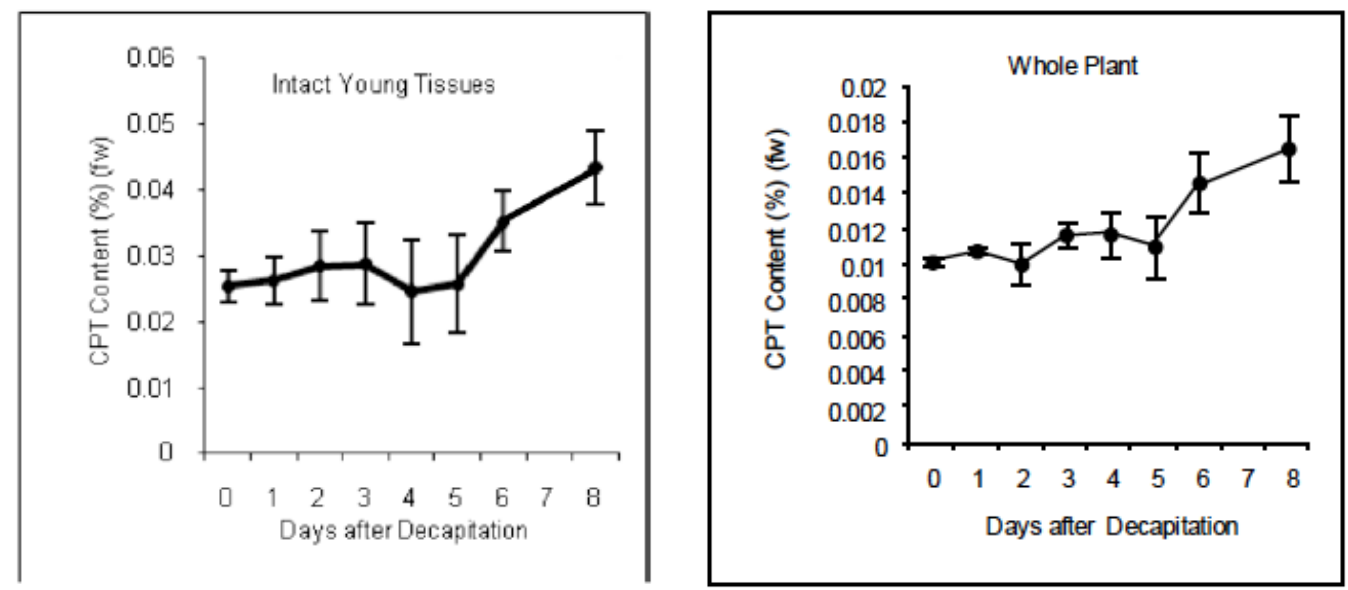

Fig. (2). Induced CPT contents in intact young tissues and whole plants of the six month-old Camptotheca acuminata seedlings by decapitation of apical bud (mean \pm s.e.).
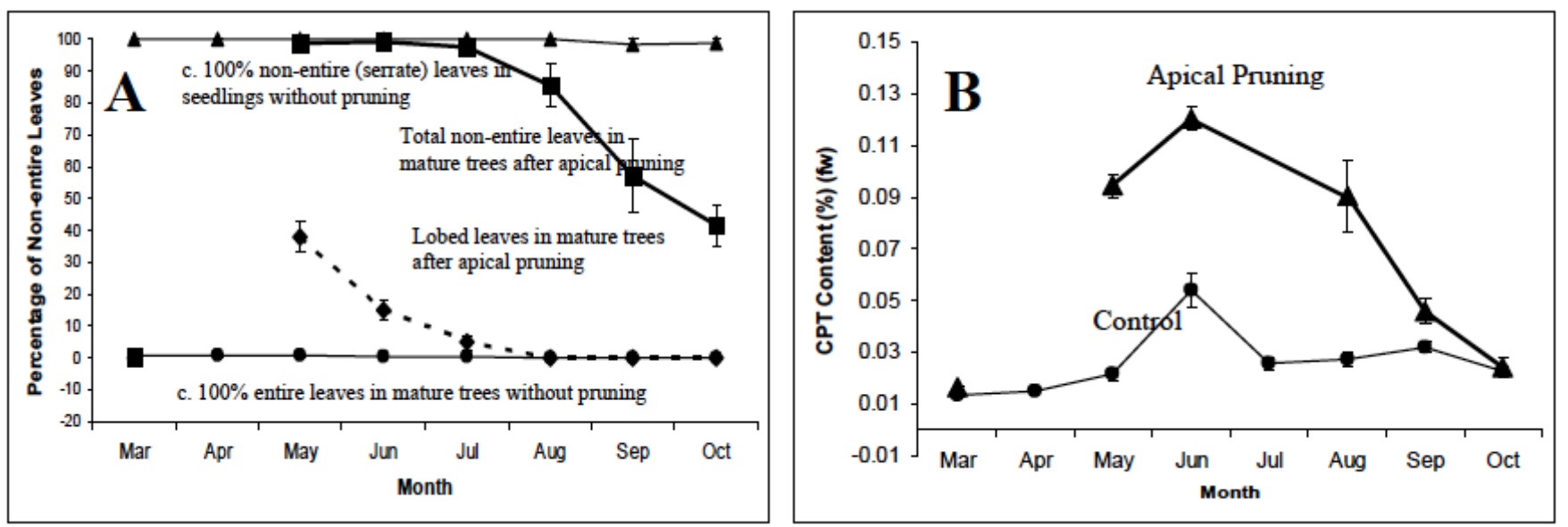

Fig. (3). Decapitation induced changes in the leaf margin patterns and CPT content in young leaves $(\leq 2$ weeks) of the 6-year-old Camptotheca acuminata trees. A: Leaf margin patterns of plants without disturbance (triangle: serrate leaves dominate in the one-year-old wildtype seedlings; dot: entire leaves dominate in the 6-year-old wild-type trees); Leaf margin pattern change of the mature trees after pruning treatment in March (square: changes of the induced non-entire (serrate and lobed) leaves over time; diamond: changes of the induced bidentate, bifid, tridentate, and trifid leaves over time). B. Changes of CPT contents in young leaves of the 6-year-old mature trees with pruning in March in comparison with untreated trees [117].

species, 35 alkaloids and triterpenoid glycosides have been isolated, including six new triterpenoid glycosides (Fig. 6) [120]. Red buckeye (Aesculus pavia) is a shrubby or small tree species commonly distributed in the southeastern U.S. From one untreated plant grown on the Stephen F. Austin State University (SFA) campus, we have isolated 14 oleanane-type triterpenoid glycosides including 12 new compounds [118]. Later, however, in addition to these compounds, we isolated 13 new additional similar compounds from another tree grown in the same location (Fig. 7) [119]. This tree had the same seed source with the above plant (previously was told from different provenance) but the terminal shoots were severely damaged by fruit collection in the previous year.

Induced Endogenous Autotoxicity (Abnormal Morphogenesis): Without disturbance, all Camptotheca species has exclusively serrate leaves during its juvenile stage (e.g., oneyear-old) and completely entire leaves when the tree becomes mature (e.g., 6-year-old) (Fig. 6) [117]. Fast-growing
Camptotheca plants can avoid poison by its endogenous camptothecin (DNA topoisomerase I inhibitor) at more than 10 times higher than the fatal concentration of exogenous application to the plant. Decapitation treatments in March alternated almost $100 \%$ newly emerged leaves in mature trees of C. acuminata to non-entire leaf margins in May: 50$76.7 \%$ serrate and $23.3-50 \%$ in other abnormal forms (e.g. bidentate, bifid, tridentate, and trifid) (Fig. 6) [117]. Nonserrate abnormal leaves during new growth gradually disappeared until August while the serrate form among new leaves gradually decreased to $41.5 \%$ in October. Decapitation also caused disturbed phyllotaxis and reduced stems. The abnormal morphogenesis appears correlatively with the elevated CPT contents following decapitation pruning [117]. Plants resume their normal morphogenesis when CPT is reduced to natural levels after stress discontinuation. The treated trees restored their normal entire leaves and phyllotaxis in the latter part of the growing season and thereafter. 

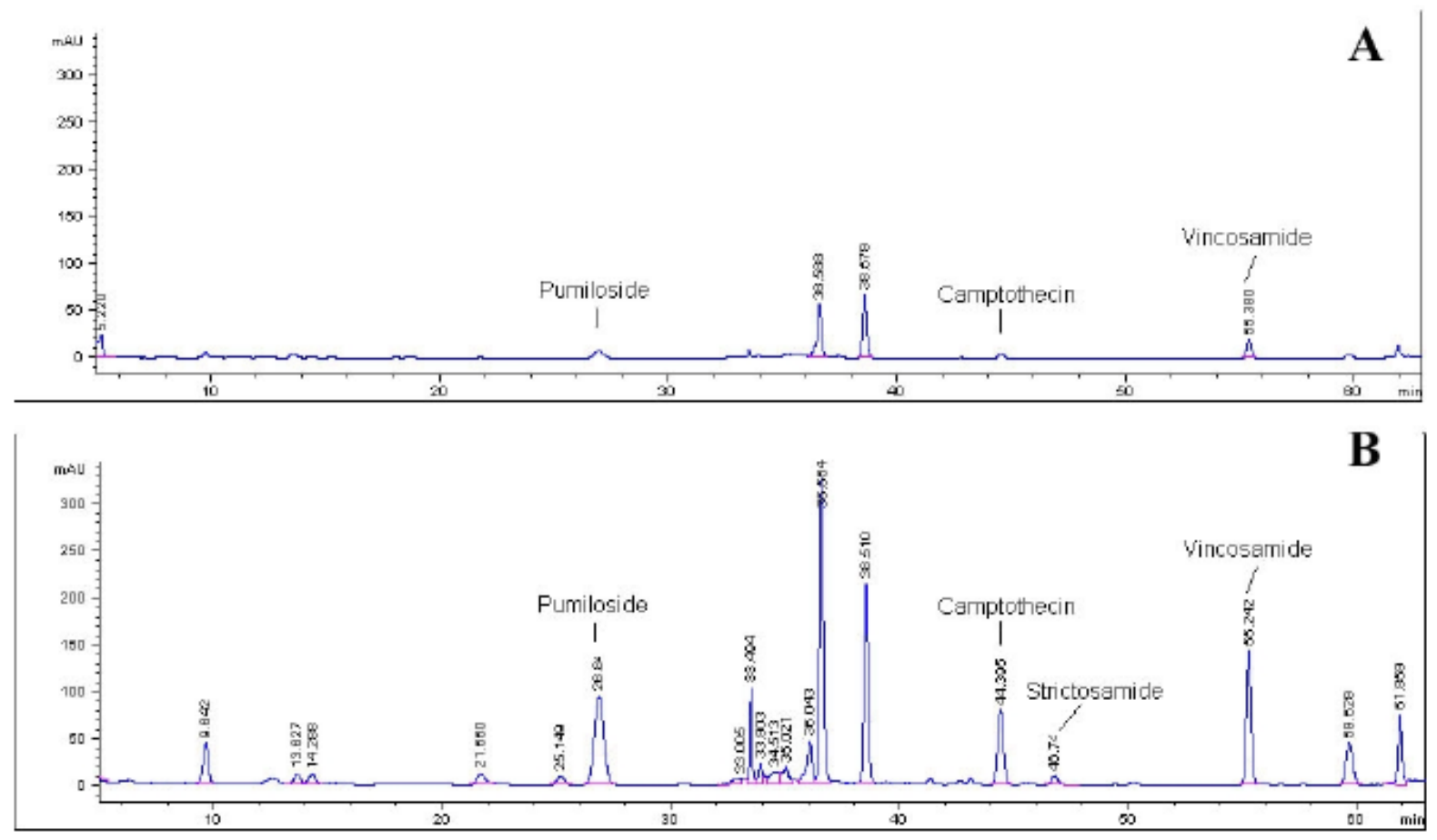

Fig. (4). HPLC chromtpgrams show significant induction of CPT and related alkaloids of in Camptotheca acuminata in both diversity and concentrations: A: before treatment and $\mathbf{B}$ : after treatment of decapitation (unpublished data).
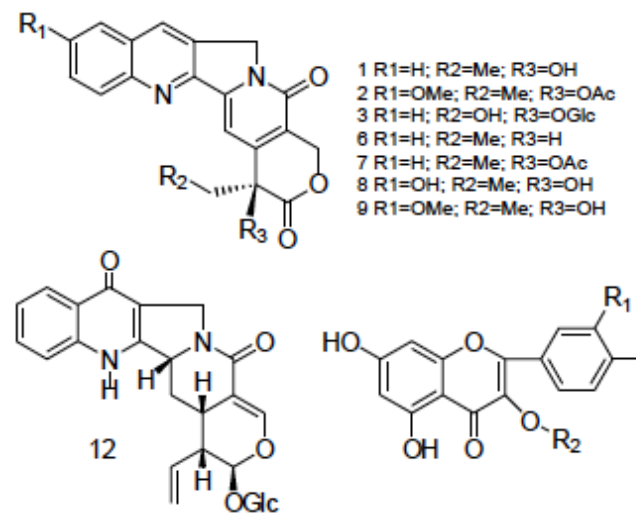<smiles>O=Cc1cccc2c(=O)n3c(cc12)-c1nc2ccccc2cc1C3</smiles>

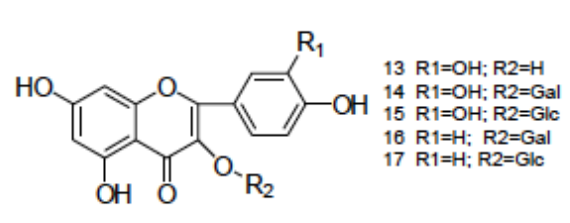

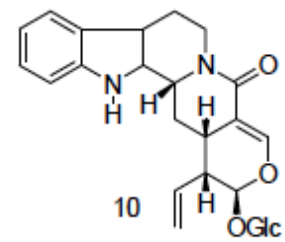
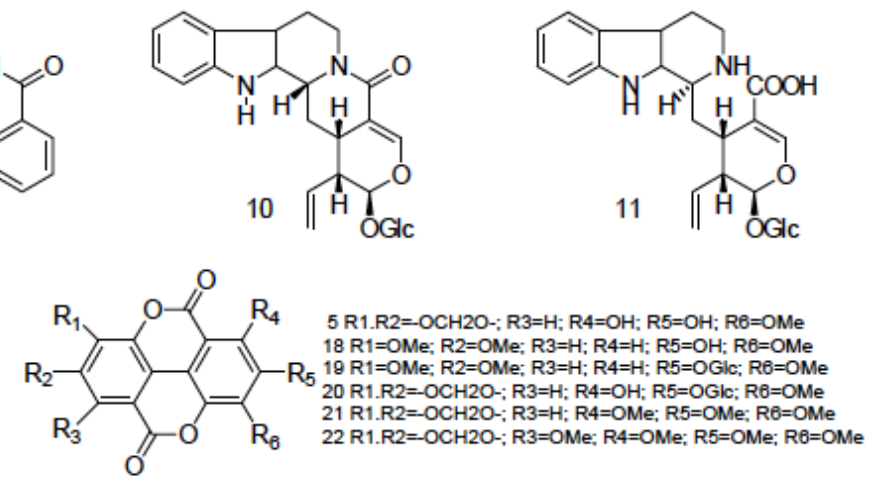

Fig. (5). 22 Natural products were isolated from root bark of Camptotheca acuminata, including CPT (1), 18 known compounds, and four new compounds (2-5) in 2004 [121].

\section{AUXIN AND CPTs}

\section{Auxin Reduction as a Trigging Factor for Induced In Vivo Biosynthesis of CPTs in Plants}

Auxin is an essential plant hormone that regulates diverse aspects of plant growth and development, particularly in controlling apical dominance of a plant and dictating normal phyllotaxis and organogenesis [122]. The important role of auxin in biosynthesis of CPTs in C. acuminata has been demonstrated in both induced CPT content (up to several folds) and increased derivatization and isolation of two new CPT derivatives (Fig. 4 and 5) [94, 116, 121]. In addition to the positive response of CPT to reducing auxin, experiments showed that pruning of lateral stems that do not involve auxin reduction did not cause changes of CPT level in any Camptotheca plants while CPT levels in C. acuminata can be significantly reduced $(10-15 \%)$ by hydroponically fed
IAA [94]. Also, we observed that the CPT content of young leaves in different Camptotheca varieties exhibits an interesting negative correlation with plant height. C. acuminata that grow up to 45 meters in height have the lowest CPT content $(0.2433 \%$ on the basis of dry weight), while our newly developed dwarf cultivar C. lowreyana 'CT168', which can only grow up to about 1 meter in height when matured, has the highest CPT content $(0.5890 \%)$ [117]. In fact, the auxin-deficient dwarf cultivars of $C$. lowreyana (either 'Katie' or 'CT168') did not have any significant change in CPT content in respond to decapitation (unpublished data). Auxin's trigging effect for inducing CPT is also demonstrated in the phenotypic restoration of dwarf 'CT168'. Our exogenous application of IAA basally to the mutant 'CT168' cuttings of higher CPT content reduced CPT levels in young leaves by about $60 \%$ and stimulated stem elongation and homogeneous leaves. Our experiments with 


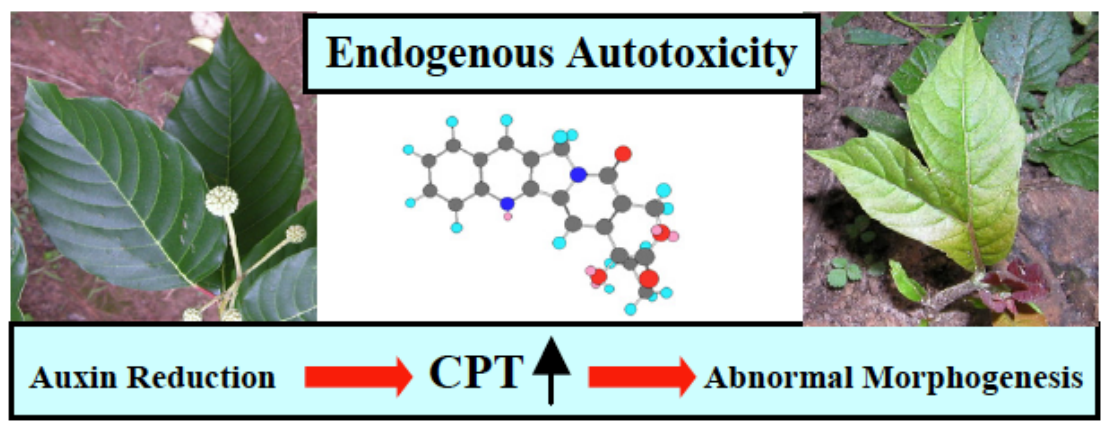

Fig. (6). Induced endogenous autotoxicity in Camptotheca acuminate by deca[itation pruning [117].

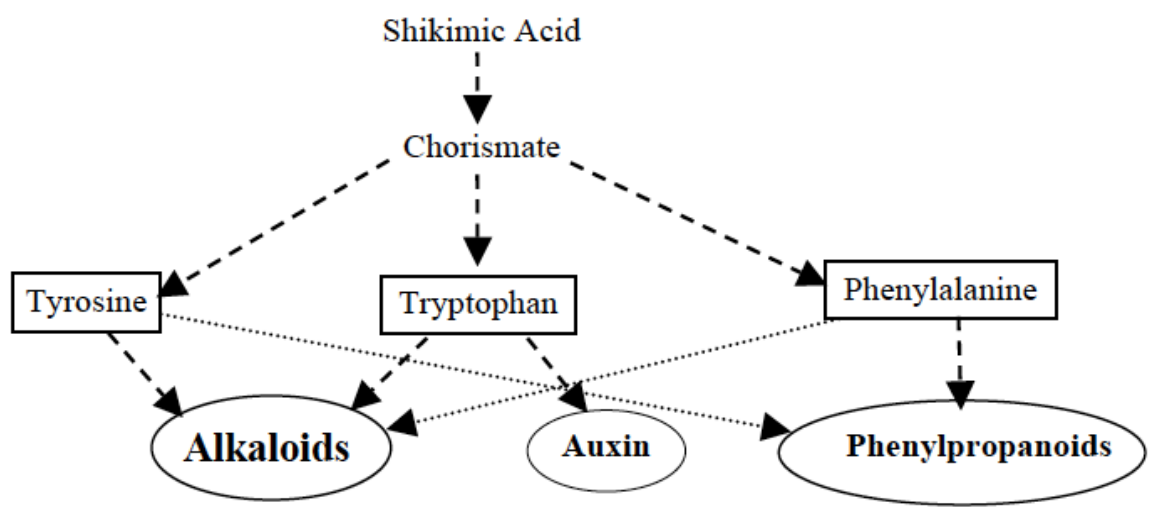

Fig. (7). Shikimate pathway.

Camptotheca futher suggest that the induced production of CPTs in plants may be caused by auxin reduction rather than auxin homeostasis because (1) the auxin deficient cultivars have higher CPT contents than normal varieties, (2) exogenous application of auxin reduces CPT levels in plants, and (3) both abnormal morphogenesis and chemical levels returned to normal after auxin homeostasis [117].

The mechanism of interaction between auxin and CPT has not been elucidated. However, CPT might have inhibitory effects on IAA as reported for hypaphorine and other indole alkaloids (32). Trp-dependent biosynthesis is also a major source for CPT. It is known that IAA is synthesized using Trp-dependent pathways in Arabidopsis, particularly in response to stress [123]. Camptotheca may use the tryptophan (Trp)-dependent route to synthesize IAA following plant wounding and when more auxin is needed. The idea that IAA and CPT share the same Trp-dependent pathways during stress could be a starting point for the investigation of their relationship.

\section{Possible Impact of Auxin-Reducing Method on Induced Biosynthesis of SMs in Plants}

It is still unclear how auxin regulates SMs in intact plants. We here speculate regarding some possible mechanisms based on partial data: Auxin may regulate biosynthesis of SMs in plants via at least shikimate and the 2-C-methylD-erythritol-4-phosphate (MEP) pathways.

The shikimate pathway is important for the biosynthesis of the aromatic amino acids Trp, tyrosine (Tyr), and phenylalanine (Phe) in plants (Fig. 7). Higher plants use these compounds for protein synthesis as well as for the produc- tion of alkaloids and phenylpropanoids (e.g., lignins, coumarins, and flavonoids). Indole-3-acetic acid (IAA, a primary and naturally occurring auxin in plants) is synthesized both from Trp using Trp-dependent pathways and from an indolic Trp precursor via Trp-independent pathways during normal growth members [123]. But plants may switch from basal Trp-independent IAA biosynthesis to Trp-dependent pathways during stress, when more IAA may be needed [124]. It was found that auxin has a negative influence on the de novo IAA biosynthesis, and IAA activates a feedback mechanism for the regulation of its own biosynthesis [124]. The IAA deduction will trigger the activity of plant Trppathway or shikimate pathway to restore homeostasis and thus produce more SMs through Trp pathways. As a result, some early metabolites of shikimate pathway (e.g., shikimic acid) could be induced by auxin. Chorismate is in the key branching point in the shikimate pathway for synthesis of Trp, Tyr, and Phe, and it shall accumulate more and flux to the Trp pathway for auxin homeostasis. It is expected that SMs via Trp pathway will be enhanced by auxin regulation, and therefore plants producing alkaloids via Trp pathways will be tested in this study. However, it is uncertain if more chorismate will be used for other aromatic amino acid pathways. This puzzle may be solved by the experiments using plants producing SMs from these two pathways (some alkaloids and phenylpropanoids).

In plant terpenoid (isoprenoids) biosynthesis, two different pathways synthesize the main building block, isopentenyl diphosphate (IPP): the MEP pathway (also named 1-deoxy$\mathrm{D}$-xylulose (DOX) pathway) in the chloroplast forms IPP for mono- and diterpenoids, and the mevalonic acid (MVA) pathway in the cytosol produces IPP for sesquiterpenoids 
and triterpenoids. Recent experiments have shown that the regulatory role of auxin on the MEP pathway leads to the biosynthesis of terpenoid indole alkaloids in Catharanthus roseus [125]. Our experiments have shown that diversity of triterpenoid glycosides in Aesculus pavia will be increased by decapitation pruning $[118,119]$ although the induced mechanism remains elusive. Thus, this study will include plants producing mono- and diterpenoids via MEP pathways and sesquiterpenoids and triterpenoids via MVA pathway.

Furthermore, alkaloids with terpene moieties (e.g., quinoline and terpenoid indole alkaloids) may be synthesized via both shikimate and MEP pathways [1, 126] and thus they may be enhanced more significantly by auxin regulation in plants than those that only use one of these two pathways. This study thus emphasizes these alkaloids by using six different species.

Plants have been recognized as a major source of lead bioactive agents. The approximately 100,000 known plant SMs were primarily extracted from natural and "undersigned" plants matters. However, most SMs have only minute concentrations in plants, so that it is difficult to obtain substantial quantities for drug production or even for basic studies. This limits the expansion of the role of host plants in drug production and development. After identification of the leading compounds with promising activities from plants, great efforts usually have turned away from the plants and focus on synthesis or biotechnological methods or metabolic engineering to enhance the production of desired compounds or to develop new derivatives. In fact, the plant is probably the best synthesis chemist and its potential has not been fully exploited.

This project tries to fill the gap by developing a new method to induce biosynthesis and derivatization of desired compounds in plants. It is expected that our new method will induce production of some SMs with too low concentrations to be isolated or detected by current technology and thus will induce biosynthesis of new compounds for the plants or completely novel compounds in nature. This will enhance the opportunities to identify novel bioactive derivatives of desired SMs and thus may provide new leads for development of more effective therapeutics or other bioactive agents. The success of this project may also lead to the development of some plants as new alternative crops with high value. Thus, it will secure the supply of some important active pharmaceutical ingredients or other important plant-derived chemicals for which we are currently largely dependent on foreign supply and will stimulate our national economy.

\section{Defense May Play Limited Roles in Induced Biosynthesis of Some Toxic SMs}

As discussed above, plant defense is the center for existing hypotheses on induced production of SMs. CPT is a potent inhibitor of topoisomerase I (topo I), a DNA replication enzyme, and stops cell division in humans and animals [127]. The role of CPT within Camptotheca plants has never been addressed. Does CPT play defensive role in Camptotheca? However, with high CPT content in young leaves of Camptotheca (up to $0.12 \%$ on the basis of fresh weight), trees can still grow up to $3 \mathrm{~m}$ in height annually with normal morphogenesis under natural conditions [116]. With CPT at the levels of 10 to 20 times higher than the minimum concentrations to inhibit fungal pathogens in vitro, Camptotheca are still infected seriously by these pathogens, particularly leaf spots and root rots [128]. It seems that cytotoxic CPT has limited bioactivity in planta in normal growth. But Camptotheca plants can not avoid endogenous autotoxicity (abnormal morphogenesis) induced by increased CPT levels. It is reported that the mutation in $T O P 1 \alpha$ caused phyllotaxis and serration of leaf margins in Arabidopsis [127]. Topo I enzyme is the primary target of CPTs. Recently, it found that some mutations of TOP1s in Camptotheca as the mechanism of self-resistance to endogenous CPT [129]. The observed auxin-induced variations in phyllotaxis and leaf margin abnormal morphogenesis of Camptotheca might be the result of TOP1 mutations which caused by induced toxic CPTs. Thus, the induced endogenous toxic CPTs likely have no defensive role in Camptotheca and they are not desirable for the plants either. The defensive role of alkaloids CPTs in Camptotheca is also challenged by our observations that herbivory, damages, or applications without significantly reducing auxin level did not increase CPT level in Camptotheca $[116,117]$. The artemisinin and taxol, two toxic terpenes from plants, may provide additional examples. Artemisinin from herbaceous Artemisia annua is one of the most widely used antimalarial drugs in the world, and diterpene paclitaxel (taxol) isolated from confers Taxus spp. is one of the commonly used anti-cancer drugs. Both plants and their chemicals are amongst the most extensively investigated, but there is no information on whether it protects the plant against herbivores and pathogens [130]. Thus, the role of chemical defense shall not be overemphasized in induced biosynthesis of some toxic SMs.

The use of auxin-reducing pruning to induce biosynthesis and derivatization of SMs would avoid the time-consuming step of acquiring knowledge about all enzymatic steps of poorly characterized biosynthetic pathways. This method is very simple and commercial feasible. Its application in Camptotheca for induced production of CPTs is a proven example [94]. The method would be particularly useful when attempts to identify more new derivatives of the desired compound. The large-scale production is possible by using a tea harvester for decapitation pruning. Unlike some other factors such as environmental stresses (e.g., drought), decapitation pruning may increase both biomass growth and biosynthesis of certain SMs as observed in Camptotheca [94]. If this advantage is confirmed in some other plants by the proposed experiments, the auxin-reducing pruning would be a desirable method for induced production of SMs. However, the effects of auxin may be absorbed by the system after the restoration of homeostasis, and thus it is important to identify the induced peak before plants resume their normal process.

It is well known that trichomes are important plant resistance traits and often contain defensive SMs. Some experiments showed that trichomes and the chemicals could be induced by herbivory in some plants [20]. This feature has been widely used to improve biological control or to enhance anti-pest/disease plant breeding in some major agricultural crops. Indeed, plants respond not only to herbivory but also to many other stresses to produce induced trichomes and SMs. Recent molecular biological studies indicated that sec- 
ondary metabolism as defense response is actually regulated by external stimuli [19]. To date, no trichome management strategy has been developed to induce production of preferred chemical compounds in plants. Because CPTs are highly accumulated in glandular trichomes on young leaves and stems, the trichomes become the management target for enhancing yield of CPTs in Camptotheca in our studies. The present invention increases production of CPTs by both accelerating new growth and increasing glandular trichome density of young leaves and stems by managing leaf trichomes.

Hormones play more important roles in trichome formation and alkaloid biosynthesis and transport in plants than we know or expected before. To understand the correlation between hormones and alkaloids is critical to developing induction strategies of alkaloids in plants. It seems difficult to present one model for correlation between hormones and trichomes or alkaloids in all plants because different species may response individually and different hormones may have different mechanisms affecting individual alkaloids. In some cases, alkaloids may be also important in hormone biosynthesis and transport. Generally, the growth promoting hormones (auxins, gebberellins, and cytokinins) inhibit biosynthesis of alkaloids while other hormones (ABA and ethylene) may stimulate the biosynthesis of alkaloids. For example, removal or decrease of auxin (IAA) will enhance the yield of indole and quinoline alkaloids in some plants (e.g. Catharanthus roseus and Camptotheca acuminata). It is not only true in cell culture of Catharanthus roseus cell culture [41, 42, 131], but also valid in the present experiments of Camptotheca plants. IAA is produced in shoot apical meristems and developing leaves and it has functions of cell elongation and inhibit growth of lateral buds (dominance). Our experiments showed that any treatments that removal or decrease IAA in plants (e.g., pruning shoot tips particularly the dominant shoots, pinching leaf tips) will stimulate the production of CPTs in Camptotheca. This explain why there is no alkaloidal induction in plants by some other pruning, pinching, or herbivory treatments those do not involve the young stem and leaf tips. This also explain multiple-shoot or slowgrowing plants usually have higher alkaloidal yield (e.g., 'Katie' and 'Hicksii'). It is not clear that how hormones inhibit the indole/quinoline alkaloids in plants. But tryptophan is a biosynthetical precursor for both indole/quinoline alkaloids and IAA (Fig. 4). The IAA route represents stimulating growth while the CPT route symbolizes for inhibiting growth. Some indole and quinoline alkaloids inhibit the cell growth through DNA Topo I enzyme or production of auxins in plants and thus are cytotoxic (anti-tumor). CPTs, vinblastine, and vincristine are examples. Some environmental stresses (drought, extreme temperature, and radiation) may stimulate alkaloidal production due to increase stress hormone (ABA) level. Our experiments showed all these stresses have positive induction of trichome/CPTs in Camptotheca. Reproductive buds or flower has richer auxin than in mature fruits. As fruit ripens, ethylene, inhibitor of auxin transport, is produced. This explains that CPTs significantly increase from flowers to mature fruits ( $\mathrm{Li}$ et al. unpublished). The relationship between alkaloids and ethylene should also be investigated.
For some pyridine alkaloids (e.g. nictotine), putrescine is a biosynthetic precursor. It has been found putrescine in cell suspensions of tobacco was determined by auxin [43]. The interrelation of hormones and alkaloids may give us reasons for why some stresses such as pruning, herbivory, and environmental changes influence alkaloidal production in plants.

Auxins are produces in shoot apical meristems, developing leaves, and reproductive buds. Thus, a plant's response to damage is determined by age and location of tissues, not merely by how to remove the tissue or how much the tissues removed.

\section{CONFLICT OF INTEREST}

The authors confirm that this article content has no conflict of interest.

\section{ACKNOWLEDGEMENTS}

Declared none.

\section{PATIENT'S CONSENT}

Declared none.

\section{REFERENCES}

[1] Verpoorte, R.; Contin, A.; Memelink, J. Biotechnology for the production of plant secondary metabolites. Phytochem. Rev., 2002, $1,13-25$.

[2] Newman, D.J.; Cragg, G.M.; Snader, K.M. Natural products as sources of new drugs over the period 1981-2002. J. Nat. Prod., 2003, 66(7), 1022-37.

[3] Capell, T.; Christou, P. Progress in plant metabolic engineering. Curr. Opin. Biotechnol., 2004, 15, 151-153.

[4] Weerawat, R.; O'Connor, S. Metabolic reprogramming of periwinkle plant culture. Nat. Chem. Biol., 2009, 5, 151-153.

[5] Rodriguez, E.; Healy, P.L.; Metha, I. Biology and chemistry of plant trichomes. Plenum Press: New York, 1984.

[6] Levin, D.A. The role of trichomes in plant defense. Quart. Rev. Biol., 1973, 48, 3-15.

[7] Metcalfe, C.R.; Chalk, L. Anatomy of the dicotyledons. Clarendon Press: Oxford, 1957; Vol. 2.

[8] Croteau, R.; Johnson, M.A. Biosynthesis of terpenoids in glandular trichomes. In: Biology and chemistry of plant trichomes; Rodriguez, E.; Healey, P.L.; Mentha, I., Eds. Plenum Press: New York and London, 1984; pp 133-185.

[9] Gershenzon, J.; Maffei, M.; Croteau, R. Biochemical and histochemical localization of monoterpene biosynthesis in the glandular trichomes of spearmint (Mentha spicata). Plant Physiol., 1989, 89, 1351-1357.

[10] Keene, C.K.; Wagner, G.J. Direct demonstration of duvatrienediol biosynthesis in glandular heads of tobacco trichomes. Plant Physiol. , 1985, 79, 1026-1032.

[11] Kitch, L.W.; Shade, R.E.; Nyquist, W.E.; Axtell, J.D. Inheritance of density of erect glandular trichomes in the genus Medicago. Crop Sci., 1985, 25, 607-611.

[12] Neuvonen, S.; Haukioja, E. The effects of inducible responses in host foliage on birch feeding herbivores. In: Phytochemical induction by herbivores, Tallamy, D.W.; Raupp, M.J., Eds. John Wiley \& Sons, Inc.: New York, 1991; pp. 277-291.

[13] Wold, E.N.; Marquis, R.J. Induced defense in white oak: Effects on herbivores and consequences for the plant. Ecology, 1997, 78(5), 1356-1369.

[14] Baldwin, I.T. The alkaloidal responses of wild tobacco to real and simulated herbivory. Oecologia, 1988, 77, 378-381.

[15] Baldwin, I.T. Damage-induced alkaloids in tobacco: Pot-bound plants are not inducible. J. Chem. Ecol., 1988, 14(4), 1113-1120.

[16] Baldwin, I.T. Short-term damage-induced increases in tobacco alkaloids protect plants. Oecologia, 1988, 75, 367-370. 
[17] Baldwin, I.T. Mechanism of damage-induced alkaloid production in wild tobacco. J. Chem. Ecol., 1989, 15 (5), 1661-1680.

[18] Baldwin, I.T. Damage-induced alkaloids in wild tobacco. In: Phytochemical induction by herbivores; Tallamy, D.W.; Raupp, M. J., Eds. John Wiley \& Sons, Inc.: New York, 1991; pp 47-69.

[19] Karban, R.; Baldwin, I.T. Induced responses to herbivory. University of Chicago Press: Chicago, 1997.

[20] Agrawal, A.A. Induced responses to herbivory and increased plant performance. Science, 1998, 279, 1201-1202.

[21] Ceska, O.; Chaudhary, S.; Warrington, P.; Poulton, G.; AshwoodSmith, M. Naturally-occuring crystals of photocarcinogenic furocumarins on surface of parsnip roots sold as food. Experientia, 1986, 42, 1302-1304.

[22] Woetz, W.G. Some effects of topping and suckering flue-cured tobacco. Station, N.C.A.E., Ed. North Carolina Agricultural Experiment Station 1955

[23] Mizusaki, S.; Tanabe, Y.; Roguchi, M.; Tamaki, E. Changes in the activities of ornithine decarboxylase, putrescine $\mathrm{N}$ methyltransferase and $\mathrm{N}$-methylputrescine oxidase in tobacco roots in relation to nicotine biosynthesis. Plant Cell Physiol., 1973, 14, 103-110.

[24] Burnett, R.J.; Maldonado-Mendoza, I.E.; McKnight, T.D.; Nessler, C.L. Expression of a 3-hydroxy-3-Methylglutaryl coenzyme a reductase gene from Camptotheca acuminata is differently regulated by wounding and methyl jasmonate. Plant Physiol., 1993, 103, 4148

[25] Beier, R.C.; Oertli, E.H. Psoralen and other linear furocumarins as phytotalexins in celery. Phytochemistry, 1983, 22, 2595-2597.

[26] Nitao, J.K. Artificial defloration and furanocoumarin induction in Pastinaca sativa (Umbellifere). J. Chem. Ecol., 1988, 14 (6), 15151521.

[27] Vincent, R.M.; Lopez-Meyer, M.; McKnight, T.D.; Nessler, C.L. Sustained Harvest of camptothecin from the leaves of Camptotheca acuminata. J. Nat. Prod., 1997, 60, 618-619.

[28] Mutikainen, P.; Walls, M. Growth, reproduction, and defence in nettles: Responses to herbivory modified by competition and fertilization. Oecologia, 1995, 104 (4), 487-495.

[29] Wink, M. Wounding-induced increase of quinolizidine alkaloid accumulation in the lupin leaves. Z. Naturforsch, 1983, 38, 905909.

[30] Wink, M. Chemical defense of lupins: Biological function of quinolizidine alkaloids. Plant Syst. Evol., 1985, 150, 65-81.

[31] Wink, M. Chemical ecology of quinolizidine alkaloids. In: Alleochemicals: Role in Agriculture and Forestry, Waller, G.R., Ed. American Chemical Society: Washington D.C., 1987; pp. 326-333.

[32] Johnson, N.D.; Rigney, L.; Bentley, B.L. Short-term changes in alkaloid levels following leaf damage in lupines with and without symbiotic nitrogen fixation. J. Chem. Ecol., 1988, 15, 2425-2434.

[33] Bentley, B.L.; Johnson, N.D.; Rigney, L. Short-term induction in leaf tissue alkaloids in lupines following experimental defoliation. Am. J. Bot., 1987, 74, 646 .

[34] Ralphs, M.H.; Williams, C. Alkaloid response to defoliation of velvet lupine (Lupinis leucophyllus). Weed Technol., 1988, 2, 429432.

[35] Fowler, S.V.; Lawton, J.H. Rapidly induced defenses and talking trees: the devil's advocate position. Am. Nat., 1985, 126, 181-195.

[36] Coleman, J.S.; Jones, C.G. A phytocentric perspective of phytochemical induction by herbivores. In: Phytochemical induction by herbivores, Tallamy, D.W.; Raupp, M.J., Eds. John Wiley \& Sons, Inc.: New York, 1991; pp. 3-45.

[37] Valentine, H.T.; Wallner, W.E.; Wargo, P.M. Nutritional changes in host foliage during and after defoliation, and their relation to the weight of gypsy moth pupae. Oecologia, 1983, 57, 298-302.

[38] Wagner, M.R.; Evans, P.D. Defoliation increases nutritional quality and allelochemics of pine seedlings. Oecologia, 1985, 67, 235-237.

[39] Owuor, P.O.; Langat, J.K.A. Changes in chemical composition of black tea due to pruning. Trop. Sci., 1988, 28, 127-132.

[40] Raven, P.H.; Evert, R.F.; Curtis, H. Biology of Plants. Worth Publishers: New York, 1981.

[41] Zenk, M.H.; El-Shagi, H.; Arens, H.; Stockigt, J.; Weiler, E.W.; Dues, B. Formation of the Indole Alkaloids Serpentine and Ajmalicine in Cell Suspension Cultures of Catharathus roseus. In: Plant tissues Culture and Cyts Biotechnological Application; Barz, W.; Reinhard, E.; Zenk, M.H., Eds. Springer-Verlag: Berlin, 1977; pp. $27-43$
[42] Pasquali, G.; Goddijn, O.J.M.; de Waal, A.; Verpoorte, R.; Schilperoort, R.A.; Hoge, J.H.C.; Memelink, J. Coordinated regulation of two indole alkaloid biosynthetic genes from Catharanthus roseus by auxin and elicitors. Plant Mol. Biol., 1992, 18(6), 121131.

[43] Tiburcio, A.F.; Kaur-Sawhney, R.; Galston, A.W. Correlation between polyamines and pyrrolidine alkaloids in developing tobacco callus. Plant Physiol., 1985, 78, 323-326.

[44] Chien, J.C.; Sussex, I.M. Differential regulation of trichome formation on the adaxial and abaxial leaf surfaces by gibberellins and photoperiod in Arabidopsis thaliana (L.) Heynh. Plant Physiol., 1996, 111, 1321-1328.

[45] El-Keltawi, N.E.; Croteau, R. Influence of phosfon D and cycocel on growth and essential oil content of sage and peppermint. Phytochemistry, 1986, 25, 1603-1606.

[46] Reichling, J.; Becker, H.; Vomel, A. Herbizide im Kamillenanbau (Matricaria chamomilla). Planta Med., 1977, 32, 235-242.

[47] El-Keltawi, N.E.; Croteau, R. Influence of ethephon and daminozide on growth and essential oil content of peppermint and sage Phytochemistry, 1986, 25, 1285-1288.

[48] El-Keltawi, N.E.; Croteau, R. Influence of foliar applied cytokinins on growth and essential oil content of several members of the Lamiaceae. Phytochemistry, 1987, 26, 891-895.

[49] Bhaumik, C.; Datta, P.C. Hormonal effect on mentholic gland initiation. Indian Biol., 1989, 21 (1), 55-57.

[50] Bosabalidis, A.M.; Exarchou, F. Effect of NAA and GA3 on leaves and glandular trichomes of Origanum $x$ intercedens Rech: Morphological and anatomical features. Int. J. Plant Sci., 1995, 156 (4), 488-495.

[51] Perazza, D.; Vachon, G.; Herzog, M. Gibberellins promote trichome formation by up-regulating GLABROUS1 in Arabidopsis. Plant Physiol., 1998, 117 (2), 375-383.

[52] Stahl, E.; Wollensah, A. Observations on the function of the glandular hairs of yarrow: $4^{\text {th }}$ report: Effects of selective herbicides on the glandular hairs and tissue of the florets. J. Plant Physiol., 1986, 122, 93-96.

[53] Liu, Z.; Adams, J.C.; Viator, H.P.; Constantin, R.J.; Carpenter, S.B. Influence of soil fertilization, plant spacing, and copping on growth, stomatal conductance, abscisic acid, and camptothecin levels in Camptotheca acuminata seedlings. Physiol. Plantarum, 1999, 105, 402-408.

[54] Good, D.E.; Snyder, J.C. Seasonal variation of leaves and mite resistance of Lycopersicon interspecific hybrids. Hort-Science, 1988, 23, 891-894.

[55] Kennedy, G.G.; Yamamoto, R.T.; Dimock, M.B.; Williams, W.G.; Bordner, J. Effect of day length and light intensity on 2-tridecanone levels and resistance in Lycopersicon hirsutum f. glabratum to Manduca Sexta. J. Chem. Ecol., 1981, 7, 707-716.

[56] Snyder, J.C.; Hyatt, J.P. Influence of daylength on trichome densities and leaf volatiles of Lycopersicon species. Plant Sci. Lett., 1984, 37, 177-181

[57] Gianfagna, T.J.; Carter, C.D.; Sacalis, J.N. Temperature and photoperiod influence trichome density and sesquiterpene content of Lycopersicon hirsutum f. hirsutum. Plant Physiol., 1992, 100, 1403-1405.

[58] Roy, B.A.; Stanton, M.L.; Eppley, S.M. Effects of environmental stress on leaf hair density and consequences for selection. J. Evol. Biol., 1999, 12, 1089-1103.

[59] Hanson, A.D.; Tully, R.E. Light stimulation of proline synthesis in water-stressed barley leaves. Planta, 1979, 145, 45-51.

[60] Pesci, P. Effects of light on abscisic acid-induced proline accumulation in leaves: Comparison between barley and wheat. Physiol. Plantarum, 1992, 86, 209-214.

[61] Liu, Z.; Carpenter, S.B.; Constantin, R.J. CPT production in Camptotheca acuminata seedlings in response to shading and flooding. Can. J. Bot., 1997, 75, 368-373.

[62] Grammatikopoulous, G.; Manetas, Y. Direct absorption of water by hairy leaves of Phlomis fruticosa and its contribution to drought avoidance. Can. J. Bot., 1994, 72, 1805-1811.

[63] Quarrie, S.A.; Jones, H.G. Effects of abscisic acid and water stress on development and morphology of wheat. J. Exp. Bot., 1977, 28, 192-203.

[64] Wellso, S.G.; Hoxie, R.P. The influence of environment on the expression of trichomes in wheat. Crop Sci., 1982, 22, 879-885. 
[65] Hoffman, A.; Shock, C.; Feibert, E. Taxane and ABA production in yew under different soil water regimes. HortScience, 1999, 34(5), 882-885.

[66] Panagopoulos, I.; Bornman, J.F.; Bjorn, L.O. Response of sugar beet plants to ultraviolet-B (280-320 $\mathrm{nm})$ radiation and Cercospora leaf spot disease. Physiol. Plantarum, 1992, 84, 140-145.

[67] Cen, Y.P.; Bornman, J.F. The effects of exposure to enhanced UV$\mathrm{B}$ radiation on the penetration of monochromomatic and polychromatic UV-B radiation in leaves of Brassica napus. Physiol. Plantarum, 1993, 87, 249-255.

[68] Vogt, T.; Gulz, P.G.; Reznik, H. UV radiation dependent flavonoid accumulation of Cistus laurifolius L.Z. Naturforsch, 1991, 46c, 3742

[69] Chaves, N.; Escudero, J.C.; Gutierrez-Merino, C. Role of ecological variables in the seasonal variation of flavonoid content of Cistus ladanifer exudate. J. Chem. Ecol., 1997, 23(3), 579-603.

[70] Karabourniotis, G.; Kotsabassidis, D.; Manetas, Y. Trichome density and its protective potential against ultraviolet-B radiation damage during leaf development. Can. J. Bot., 1995, 73, 376-383.

[71] Ziska, L.H.; Teramura, A.H.; Sullivan, J.H.; McCoy, A. Influence of ultraviolet-B (UV-B) radiation on photosynthetic and growth characteristics in field-grown cassava (Manihot esculentum Crantz). Plant Cell Environ., 1993, 16, 73-79.

[72] Karabourniotis, G.; Kofidis, G.; Fasseas, C.; Liakoura, V.; Drossopoulos, I. Polyphenol deposition in leaf hairs of Olea europaea (Oleaceae) and Quercus ilex (Fagaceae). Am. J. Bot., 1988, 85(7), 1007-1012.

[73] Karabouniotis, G.; Papadopoulos, K.; Papamarkou, M.; Manetas, Y. Ultraviolet-B radiation absorbing capacity of leaf hairs. Physiol. Plant, 1992, 86 (3), 414-418.

[74] Skaltsa, H.; Verykokidou, E.; Harvala, C.; Karabouniotis, G.; Manetas, Y. UV-B protective potential and flavonoid content of leaf hairs of Quercus ilex. Phytochemistry, 1994, 37, 987-990.

[75] Karabourniotis, G.; Bornman, J.F. Penetration of UV-A, UV-B and blue light through the leaf trichome layers of two xeromorphic plants, olive and oak, measured by optical fibre microprobes. Physiol. Plantarum, 1999, 105, 655-661.

[76] Nagata, T.; Todoriki, S.; Hayashi, T.; Shibata, Y.; Mori, M.; Kanegae, H.; Kikuchi, S. g-Radiation induces leaf trichome formation in Arabidopsis. Plant Physiol., 1999, 120, 113-119.

[77] Hulskamp, M.; Misera, S.; Jurgens, G. Genetic dissection of trichome cell development in Arabidopsis. Cell, 1994, 76, 555-556.

[78] Marks, M.D.; Oppenheimer, D.G.; Garon, E. Analysis of clonal sectors of altered epidermis on EMS treated Arabidopsis plants. Weeds World, 1996, 2, 1-5.

[79] Kangasjarvi, J.; Talvinen, J.; Utriainen, M.; Karjalainen, P. Plant defence systems induced by ozone. Plant Cell Environ., 1994, 17, 783-794.

[80] Loomis, W.E. Growth and Differentiation in Plants. Iowa State University Press: Ames, 1953

[81] Bryant, J.P.; Chapin, F.S.; Klein, D.R. Carbon/nutrient balance of boreal plants in relation to vertebrate herbivory. Oikos, 1983, 40, 357-368.

[82] Haslam, E. Secondary metabolism: Fact and fiction. Nat. Prod. Rep., 1986, 3, 217-249.

[83] Chapin, F.S. Integrated responses of plants to stress. Bioscience, 1991, 41, 29-36.

[84] McKey, D. Adaptive patterns in alkaloid physiology. Am. Nat., 1974, 108, 305-320.

[85] Zangerl, A.R.; Bazzaz, F.A. Theory and pattern in plant defense allocation. In: Plant resistance to herbivoves and pathogens; Fritz, S.; Simms, E.L., Eds. University of Chicago Press: Chicago, 1992; pp 363-391.

[86] van Dam, N.M.; Verpoorte, L.W.M.; van Der Meijden, E. Extreme differences in pyrrolizidine alkaloid levels between leaves of $G y$ noglossum. Phytochemistry, 1994, 37, 1013-1016.

[87] Berryman, A.A. Towards a unified theory of plant defense. In: Mechanisms of woody plant defense against insects, Mattson, W.J.; Levieux, J.; Bernard-Dagan, C., Eds. Springer-Verlag: New York, 1988; pp. 39-55

[88] Lyons-Johnson, D. Understanding sugar transport in plants. Agric. Res., 47(3), 1999, 9

[89] Strauss, E. RNA molecules may carry long distance signals in plants. Science, 1999, 283 (5398), 12-13

[90] Liu, Z.; Carpenter, S.B.; Bourgeois, W.J.; Yu, Y.; Constantin, R.J.; Falcon, M.J.; Adams, J.C. Variations in the secondary metabolite camptothecin in relation to tissue age and season in Camptotheca acuminata. Tree Physiol., 1998, 18, 265-270.

[91] Li, S.Y.; Adair, K.T. Camptotheca acuminata Decaisne, Xi Shu, A Promising Anti-tumor and Anti-viral Tree for the $21^{\text {st }}$ Century. Henry M. Rockwell Monograph, Stephen F. Austin State University: Nacogdoches, 1994

[92] Hsu, J.S.; Chao, T.Y.; Hsu, J.S. Chemical constituents of the anticancer plant Camptotheca acuminata Decne (I). Acta Chim. Sin., 1977, 35, 227-231

[93] Hsu, J.S.; Chao, T.Y.; Lin, L.T.; Hsu, C.F. Chemical constituents of the anticancer plant Camptotheca acuminata Decne. II. Chemical constituents of the fruits of Camptotheca acuminata Decne. Acta Chim. Sin., 1977, 35, 193-200.

[94] Li, S.Y.; Yi, Y.J.; Wang, Y.J.; Zhang, Z.Z.; Beasley, R.S. Camptothecin accumulation and variation in Camptotheca Decaisne. Planta Med., 2002, 68(11), 1010-1016.

[95] Wall, M.E.; Wani, M.C.; Cook, C.E.; Palmer, K.H.; McPhail, A.T.; Sim, G.A. Plant antitumor agents. I. The isolation and structure of Camptothecin, a novel alkaloidal leukemia and tumor inhibitor from Camptotheca acuminata. J. Am. Chem. Soc., 1966, 88, 38883890.

[96] Perdue, R.E.; Smith, R.L.; Wall, M.E.; Hartwell, J.L.; Abbot, B.J. Camptotheca acuminata Decaisne (Nyssaceae) source of camptothecin, and antileukemic alkaloid. Agricultural Research Series, U., Ed. Agricultural Research Series, USDA: 1970.

[97] Tien, H.J.; Tien, J.M.; Yeh, M.Y.; Wu, T.S.; Huang, C.M. Studies on the constituents of Camptotheca acuminata Done (I). The constituents of leaves. Chemistry, 1977, 1977(2), 51-54.

[98] Cao, G.R.; Gao, J.X.; Duan, D.X.; Li, S.J.; Wang, K. Studies on Camptotheca acuminata leaves: Main toxic principle, poisoning, and treatment in goats. In: Poisoning Plants: Proceedings of the Third International Symposium, James, L.F.; Keeler, R.F.; Bailey, E.M.; Cheeke, P.R.; Hegarty, M.P., Eds.; Iowa State University Press: Ames, 1992; pp. 495-499.

[99] Lopez-Meyer, M.; Nessler, C.L.; McKnight, T.D. Sites of accumulation of the antitumor alkaloid camptothecin in Camptotheca acuminata. Planta Med., 1994, 60, 558-560.

[100] Shimomura, K.; Yoshimatsu, K.; Jaziri, M.; Ishimaru, K. Traditional medicinal plant genetic resources and biotechnology applications. In: Plant Biotechnology and Plant Genetic Resources for Sustainability and Productivity, Watanabe, K.; Pehu, E., Eds. R.G. Lands Company: Austin, 1997; pp. 209-225.

[101] LI, S.Y. Camptotheca lowreyana, a new species of anti-cancer happytrees. Bull. Bot. Res., 1997, 17(3), 348-352.

[102] McKey, D. The distribution of secondary compounds within plants. In: Herbivores. Their interactions with secondary plant metabolites, Rosenthal, G.A.; Janzen, D.H., Eds.; Academic Press: New York, USA, 1979; pp. 56-133.

[103] Tingey, W.M.; Laubengayer, J.E. Defense against the green peach aphid and potato leafhopper by glandular trichomes of Solanum berthaultii. J. Econ. Entomol., 1981, 74, 721-725.

[104] van Dam, N.M.; Verpoorte, R.; van Der Meijden, E. Extreme differences in pyrrolizidine alkaloid levels between leaves of Gynoglossum officinale. Phytochemistry, 1994, 37, 1013-1016.

[105] Liu, Z.; Adams, J. Camptothecin yield and distribution within Camptotheca acuminata trees cultivated in Louisiana. Can. J. Bot., 1996, 74, 360-365.

[106] Severson, R.F.; Johnson, A.W.; Jackson, D.M. Cuticular constituents of tabacco: Factors affecting their production and their role in insect and disease resistance and smoke quality. Rec. Adv. Tobacco Sci., 1985, 11, 105-174.

[107] Wagner, G.J. Secreting glandular trichomes: more than just hairs. Plant Physiol., 1991, 96, 675-679.

[108] Kennedy, B.S.; Nielsen, M.T.; Severson, R.F.; Sisson, V.A.; Stephenson, M.K.; Jackson, D.M. Leaf surface chemicals from Nicotiana affecting germination of Peronospora tabacina (Adam) sporangia. J. Chem. Ecol., 1992, 18, 1467-1479.

[109] van Hengel, A.J.; Harkes, M.P.; Wichers, H.J.; Hesselink, G.M.; Buitelaar, R.M. Characterization of callus formation and camptothecin production by cell lines of Camptotheca acuminata. Plant Cell Tiss. Org., 1992, 28, 11-18.

[110] Lu, H.; McKnight, T.D. Tissue-specific expression of the $\beta$-subunit of tryptophan synthase in Camptotheca acuminata, an indole alkaloid-producing plant. Plant Physiol., 1999, 120, 43-52.

[111] Cook, A.D. Pruning techniques. Brooklyn Botanical Garden: Brooklyn, 1991. 
[112] Medic, K. Rodale's successful organic gardening: Pruning. Rodale Press: Emmaus, 1995

[113] Wade, G.L.; Westerfield, R.R. Basic principles of pruning woody plants; Cooperative Extension Services, College of Agriculture \& Environmental Sciences, University of Georgia: Athens, 1999.

[114] Bedker, P.J.; O'Brien, J.G.; Mielke, M.E. How to prune trees. Radnor, PA: USDA Forest Service, Northeastern area state and private forestry, 1995 ; p. 30.

[115] Ouellette, D.R.; Young, E. Branch inducement in apple stoolbed shoots by summer leaf removal and tipping. HortScience, 1994, 29, 1478-1480.

[116] Li, S.Y. A system for increasing the production of indole and quinoline alkaloids, particularly camptothecins and related compounds, from plants. R.O. China Invention 162720, 2002.

[117] Li, S.Y.; Wang, P.; Yuan, W. Induced endogenous autotoxicity in Camptotheca. Front. Biosci., 2010, E2, 1196-1210.

[118] Zhang, Z.Z.; Li, S.Y.; Zhang, S.M.; Gorenstein, D. Triterpenoid saponins from the fruits of Aesculus pavia. Phytochemistry, 2006, 67, 784-794.

[119] Zhang, Z.Z.; Li, S.Y. Cytotoxic triterpenoid saponins from the fruits of Aesculus pavia L. Phytochemistry 2007, 68, 2075-2086.

[120] Zhang, Z.; Li, S.Y.; Zhang, S. Six new triterpenoid saponins from the root and stem bark of Cephalanthus occidentalis L. Planta Med., 2005, 71, 355-361.

[121] Zhang, Z.Z.; Li, S.Y.; Zhang, S.M.; Liang, C.; Gorenstein, D.; Beasley, R.S. New Camptothecin and ellagic acid analogues from the root bark of Camptotheca acuminata. Planta Med., 2004, 70(12), 1216-1221.

[122] Dharmasiri, N.; Dharmasiri, N.; Estelle, M. The F-box protein TIR1 is an auxin receptor. Nature, 2005, 435, 441-445.
[123] Woodward, A.W.; Bartel, B. Auxin: regulation, action, and interaction. Ann. Bot. London, 2005, 95, 707-735.

[124] Ribnicky, D.M.; Cohen, J.D.; Hu, W.S.; Cooke, T.J. An auxin surge following fertilization in carrots: a mechanism for regulating plant totipotency. Planta, 2002, 214, 505-509.

[125] Hedhili, S.; Courdavault, V.; Giglioli-Guivarc, H.; Gantet, P. Regulation of the terpene moiety biosynthesis of Catharanthus roseus terpene indole alkaloids. Phytochem. Rev., 2007, 6, 341-351.

[126] Lorence, A.; Medina-Bolivar, F.; Nessler, C.L. Camptothecin and 10-hydroxycamptothecin from Camptotheca acuminata hairy roots. Plant Cell Rep., 2004, 22, 437-441.

[127] Takahashi, T.; Matsuhara, S.; Abe, M.; Komeda, Y. Disruption of a DNA topoisomerase I Gene Affects Morphogenesis in Arabidopsis. Plant Cell, 2002, 14, 2085-2093.

[128] Li, S.Y.; Zhang, Z.Z.; Cain, A.; Wang, P.; Long, M.; Taylor, J. Anti-fungal activity of camptothecin, trifolin, and hyperoside isolated from Camptotheca acuminata. J. Agric. Food Chem., 2005, 53, 32-37.

[129] Sirikantaramas, S.; Yamazaki, M.; Saito, K. Mutations in topisomerase I as a self-resistance mechanism coevolved with the production of the anticancer alkaloid camptothecin in plants. Proc. Natl. Acad. Sci., 2008, 105, 6782-6786.

[130] Gershenzon, J.; Dudareva, N. The function of terpene natural products in the natural world. Nat. Chem. Biol., 2007, 3, 408-414.

[131] Gantet, P.; Imbault, N.; Thiersault, M.; Doireau, P. Necessity of a functional octadecanoic pathway for indole alkaloid synthesis by Catharanthus roseous cell suspensions cultured in an auxin-starved medium. Plant Cell Physiol., 1998, 39(2), 220-225.

(C) Li et al.; Licensee Bentham Open.

This is an open access article licensed under the terms of the Creative Commons Attribution Non-Commercial License (http://creativecommons.org/licenses/by-nc/3.0/) which permits unrestricted, non-commercial use, distribution and reproduction in any medium, provided the work is properly cited. 